\title{
Seismic damage to schools subjected to Nepal earthquakes, 2015
}

\author{
Hao Chen ${ }^{1}$ Quancai Xie ${ }^{1}$ Riqing $\operatorname{Lan}^{2} \cdot$ Zhiqiang $\mathrm{Li}^{3}$ • \\ Chong $\mathrm{Xu}^{3} \cdot$ Shizhou $\mathrm{Yu}^{1}$
}

Received: 29 August 2016/Accepted: 7 April 2017/Published online: 18 April 2017

(C) The Author(s) 2017. This article is an open access publication

\begin{abstract}
Schools are the gathering place of the young generation. They are expected to act as a refuge after an earthquake. Even though Nepal has no building supervision system, the quality of school buildings receives necessary attention. During a field study conducted in mid-June, we summarised the seismic damage to 12 schools with various types of structures, including local characteristic reinforced concrete frames, cement-bonded or mud-bonded masonry and timber frames. The pros and cons of local construction technologies are discussed. Some interesting earthquake phenomena, such as the effects of forward directivity, site configuration, earthquake sequence and safe distance from a slope, are discussed. The geo-security evaluation of a proposed school site in mountainous Baramchi is also conducted.
\end{abstract}

Keywords Nepal earthquake 2015 - School - Directivity effect - Site effect · Earthquake sequence

\section{Introduction}

On 25 April 2015, the Gorkha earthquake of Mw 7.8 struck Nepal, followed by many powerful aftershocks, four of $\mathrm{Mw} \geqq 6.3$, by 6 October (NSC 2015). It was reported that the series of earthquakes caused 8790 deaths, 22,300 injured, and millions of houses demolished (NPCGN 2015). NPCGN also reported that many houses in Nepal did not have an aseismic design and were constructed by local artisans without building supervision

Riqing Lan

lanriqing2003@163.com

1 Institute of Engineering Mechanics, China Earthquake Administration, Langfang 150080, Hebei, China

2 Institute of Geophysics, China Earthquake Administration, Langfang 150080, Hebei, China

3 Institute of Geology, China Earthquake Administration, Langfang 150080, Hebei, China 
system to guarantee the quality of construction, especially in rural and/or mountainous areas. The catastrophe of numerous self-built non-engineered buildings leaves us nothing to learn for aseismic design improvement. Many researchers have published papers on the field reconnaissance of the mega earthquake sequences. High-intensity damages were found in ancient temples (Rai et al. 2016b), residential buildings inside and outside Kathmandu Valley (Rai et al. 2016a; Chen et al. 2016). However, some public gathering places, such as schools, shopping malls and hospitals, received necessary attention, which is also reflected in the Nepal Building Codes (NBC105 1994).

As the pre-earthquake gathering place of the young generation and a post-earthquake shelter or refuge, the aseismic performance of schools should be guaranteed. The San Francisco Planning and Urban Research Association (SPUR) proposed a recovery plan for various types of important infrastructures under an expected earthquake scenario (including a $10 \%$ probability of occurrence in 50 years) (Poland 2009). The report stipulated that schools should be able to accommodate refugees within $72 \mathrm{~h}$ and recover to full service within 30 days. The school facilities and the interdependent topology with other infrastructure are illustrated in Fig. 1. A school usually consists of buildings, a crew, teaching materials and research/experiment facilities. The non-structural components are not as valuable or complex as those of a hospital. They normally have a low price and are easy to fix, such as blackboards, tables, chairs, lights, shelves and some common electricity and water supply/drainage systems. Compared with a hospital with a complex system, a school is less dependent on other infrastructure because no special services are needed and because the normal function of a school can be halted and transferred to house refugees in an emergency situation. A school normally has many wide bay classrooms, increasing the aseismic capacity requirement. Thus, the focus of this paper is on the structural damage to various kinds of school buildings distributing in areas with high seismic intensity. Special earthquake phenomena, such as the forward-directivity effect, site effect and earthquake sequence effect, were observed and are explained. The pros and cons of local design are also discussed in detail.

As an earthquake-prone area and an undeveloped country without solid industry, rapid recovery from such a massive earthquake is unimaginable without outside aid. India, the USA, China, Australia and many other countries, and some international organisations have provided money, equipment, emergency relief and various kinds of experts to help in the recovery. China's Ministry of Commerce supported 22 earthquake engineers to investigate the seismic hazards in and around the Rasuwa and Sindhupalchok districts from 5 to 20 June.

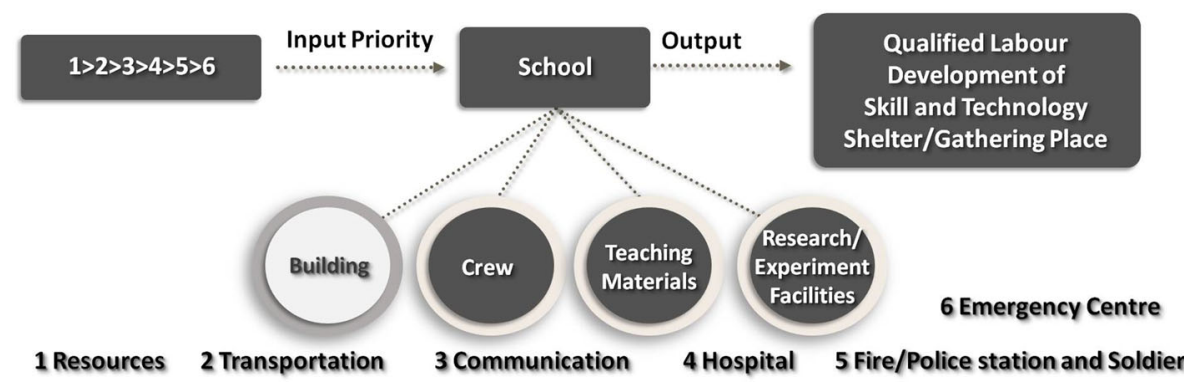

Fig. 1 Interdependence topology of school with other infrastructures 
Figure 2 plots the intensity map with a seismic intensity of VII to IX generated on the basis of field study data collected from all members (GAQSIQ 2008; Sun and Yan 2015). The assemblies of buildings over a total of $168,290 \mathrm{~km}^{2}$ were investigated. The areas with intensities IX, VIII and VII are estimated to be 900,2330 and $165,060 \mathrm{~km}^{2}$, respectively. The authors found 12 schools on the trip, including 6 with reinforced concrete frames, 5 with masonry (both mud bonded and cement bonded) and 1 with a timber frame. The locations of these structures are marked in Fig. 2 for geological information reference. The damage matrix of school houses in areas with seismic intensity VII to IX is summarised in Table 1 as well as the overall inspected buildings $\left(5,194,384 \mathrm{~m}^{2}\right.$ mud-bonded masonry, $722,323 \mathrm{~m}^{2}$ cement-bonded masonry and 4,132,401 $\mathrm{m}^{2} \mathrm{RC}$ frame). The seismic extent is defined as following. For masonry structure designed according to seismic fortification level VII, the extent of damage is classified into five levels from light to severe (GAQSIQ 2008): almost intact [less than 10\% non-load-bearing components (NLBC) are damaged, but function well], light [less than 10\% load-bearing components (LBC) have visible crack. Minor or no repair is needed], moderate (40-70\% of the LBC have visible crack. Some of them have apparent cracks), severe (partial collapse, 40-70\% LBC crack severely and hard to repair) and collapse (most of the LBC fail or collapse totally beyond repair). Seismic intensities VII, VIII and IX indicate 10-45\% masonry structure with seismic fortification level VII has moderate/light damage, severe/moderate damage and collapse/severe damage, respectively (GAQSIQ 2008).

Section 2 introduces the records and spectra analyses of five strong motion stations installed by USGS and Japanese researchers. In spite of limited available strong motion records, the predicted/estimated peak acceleration records by other researches are introduced and verified by field study. The rupture process of the main shock is also discussed, which helps discuss the direction effect on the failure mechanics of two perpendicularly

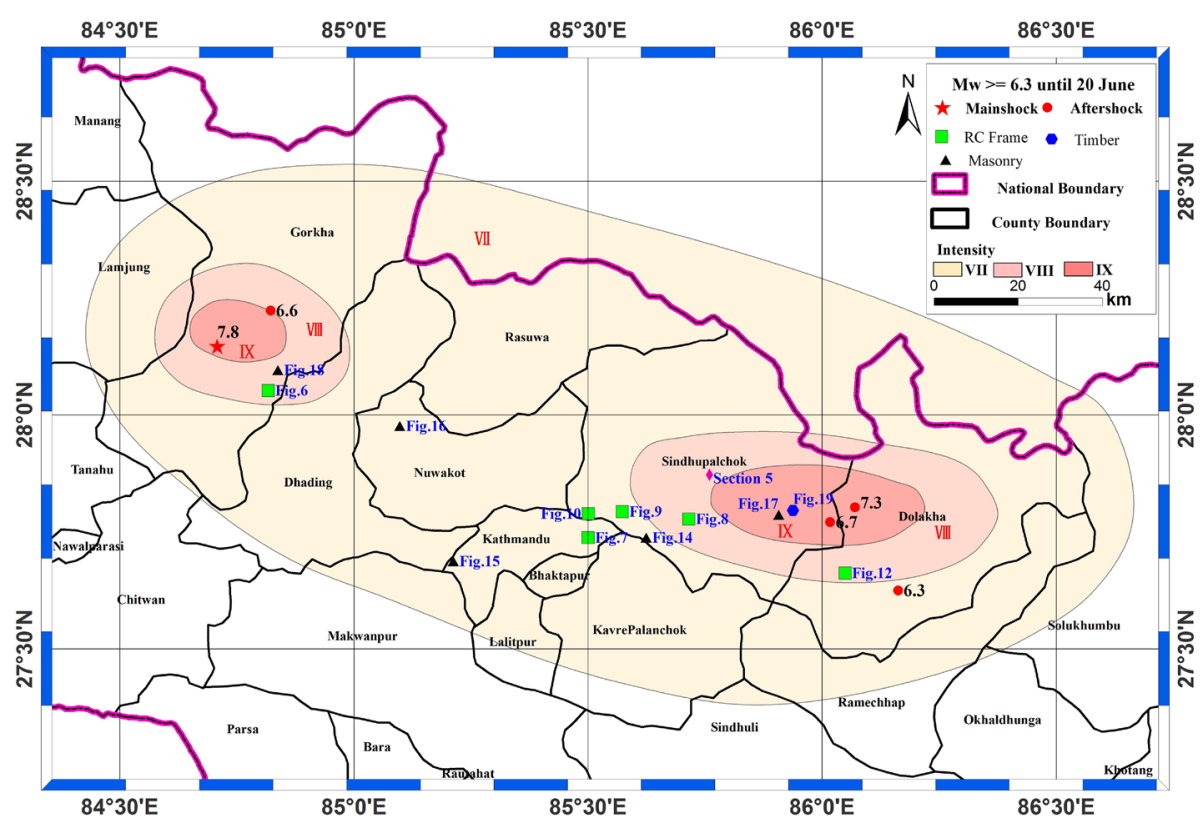

Fig. 2 Seismic intensity map and location of following figures 
Table 1 Earthquake damage matrix for mud-bonded masonry, cement-bonded masonry and RC frame of investigated school buildings $\left(\mathrm{m}^{2}\right)$ in area with seismic intensity VII, VIII and IX (GAQSIQ 2008)

\begin{tabular}{|c|c|c|c|c|c|}
\hline Damage extent & Collapse & Severe & Moderate & light & Almost intact \\
\hline Seismic intensity & \multicolumn{5}{|l|}{ VII } \\
\hline Cement-bonded masonry & - & - & $570 \mathrm{~m}^{2}$ & $882 \mathrm{~m}^{2}$ & $540 \mathrm{~m}^{2}$ \\
\hline $\mathrm{RC}$ frame & - & - & $1520 \mathrm{~m}^{2}$ & $1270 \mathrm{~m}^{2}$ & - \\
\hline Seismic intensity & \multicolumn{5}{|l|}{ VIII } \\
\hline Mud-bonded masonry & $1010 \mathrm{~m}^{2}$ & - & - & - & - \\
\hline Cement-bonded masonry & - & $160 \mathrm{~m}^{2}$ & $740 \mathrm{~m}^{2}$ & $140 \mathrm{~m}^{2}$ & - \\
\hline $\mathrm{RC}$ frame & - & $2280 \mathrm{~m}^{2}$ & $1860 \mathrm{~m}^{2}$ & - & - \\
\hline Seismic intensity & \multicolumn{5}{|l|}{ IX } \\
\hline Mud-bonded masonry & $45 \mathrm{~m}^{2}$ & $190 \mathrm{~m}^{2}$ & - & - & - \\
\hline Evaluation scope & \multicolumn{5}{|c|}{$\begin{array}{l}\text { Overall damage matrix including all inspected buildings (\%) (Chen et al. 2016) } \\
\text { IX, VIII and VII are estimated to be } 900,2330 \text { and } 165,060 \mathrm{~km}^{2}\end{array}$} \\
\hline Mud-bonded masonry & 36.18 & 23.62 & 26.45 & 10.36 & 3.39 \\
\hline Cement-bonded masonry & 7.19 & 22.42 & 25.62 & 27.74 & 17.02 \\
\hline $\mathrm{RC}$ frame & 1.38 & 8.72 & 15.75 & 35.98 & 38.17 \\
\hline
\end{tabular}

arranged similar RC frames of Shree Saraswati Higher Secondary School. The seismic damages are introduced in terms of structural types including RC frames, masonry and timber frame from Sects. 3 to 5, respectively. China has decided to donate a school near Baramchi in the mountainous Sindhupalchok district $\left(85^{\circ} 45^{\prime} 34.1^{\prime \prime} \mathrm{E}, 27^{\circ} 52^{\prime} 20.2^{\prime \prime} \mathrm{N}\right)$. The location was assigned by the local government. Safety evaluation of the proposed location is conducted in Sect. 6. Finally, a summary and recommendations for the reconstruction plan are given in Sect. 7.

\section{The records and predicted ground motion around investigated spots}

\subsection{Available ground motion records and the spectrum analyses}

The records of six strong motion stations located in Kathmandu are available, including KATNP, QCN, KTP, TVU, PTN and THM stations (Fig. 3 for location reference). The first two are installed by USGS (USGS 2015), whilst the other four are installed by Japanese researchers (Takai et al. 2016). Only KTP is located on the rock, and all others are located at soft sedimentary sites. QCN was a temporary station installed after the main shock.

The fault size of the main shock was estimated to be approximate $200 \mathrm{~km} \times 150 \mathrm{~km}$ by USGS (2015) and $120 \mathrm{~km} \times 80 \mathrm{~km}$ by Yagi and Okuwaki (2015) (Fig. 4). Both of them report a large-slip area near the Kathmandu Valley. The velocity and displacement were calculated by integrating the acceleration time history, which was processed by linear baseline correction and a Butterworth filter (Table 2). The largest corrected peak ground acceleration/velocity/displacement was the EW component at the KTP station $(256.5 \mathrm{~cm} /$ $\mathrm{s}^{2}$ ), the UD component at the TVU station $(101.1 \mathrm{~cm} / \mathrm{s})$ and the UD component at KATNP station $(-71.7 \mathrm{~cm})$, respectively. The corrected accelerograms and the spectrum analyses 


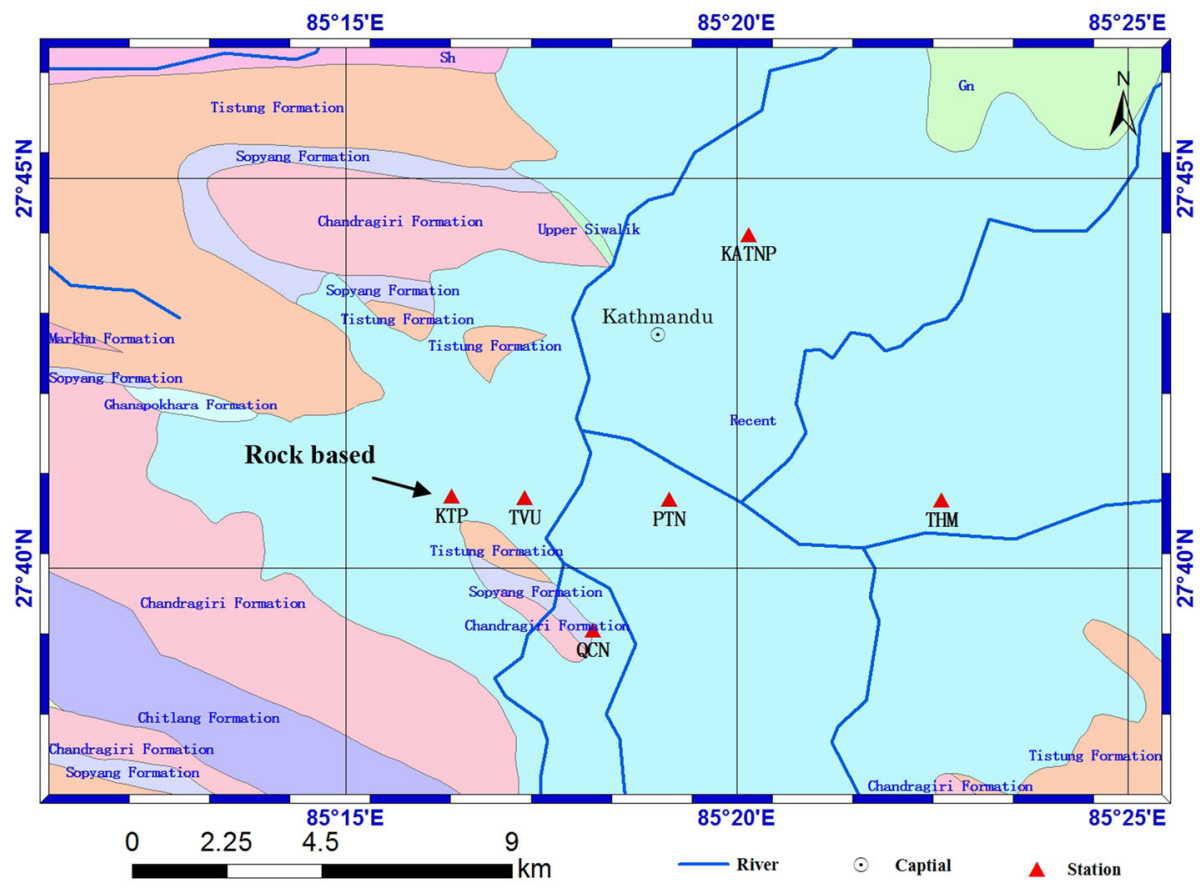

Fig. 3 The distribution of the strong motion stations (KATNP was provided by USGS (2015). KTP, TVU, PTN and THM are referred to Takai et al. (2016). QCN is a temporary station installed after the main shock by USGS

of the main shock recorded by the five stations are plotted in Fig. 4. KTP station is rich in the short-period component between 0.1 and $0.4 \mathrm{~s}$ in all three directions, since it located at rock. The horizontal spectra of all other four soil-based stations have obvious crests or rich components around 1-5 s. The reasons for the richness in the long-period components are explained by Galetzka et al. (2015) that the whole basin resonates at a period of 4-5 s, resulting from the combined effects of the slow rupture procedure (6-s duration with $1.1 \mathrm{~m} /$ s peak velocity slip pulse propagates to Kathmandu at $\sim 3.3 \mathrm{~km} / \mathrm{s}$ ) and the thick sediment (around $600 \mathrm{~m}$ ) site condition in the Kathmandu basin. The seismic loss was far less than expectation under such a large earthquake in Kathmandu due to the prevailing low rigid structure (normally 3- to 5-storey high RC frame and masonry). However, high buildings, even the newly constructed mansions of high quality, were damaged moderately/severely (Chen et al. 2016).

\subsection{Prediction of ground motion distribution by ground motion prediction equations (GMPE)}

The ground motion prediction equation proposed by Boore et al. (2014) and $\mathrm{Si}$ and Midorikawa (2000) is compared with strong motion station records, and it was found that the estimated value is larger than the observed ones for both of the equations (Takai et al. 2016). Ahmad and Singh (2016) compared the observed ground motion parameters of the main shock with the estimated ground motion parameters from the existing attenuation relations of the Himalayan region. The PGA was computed based on Modified Mercalli 

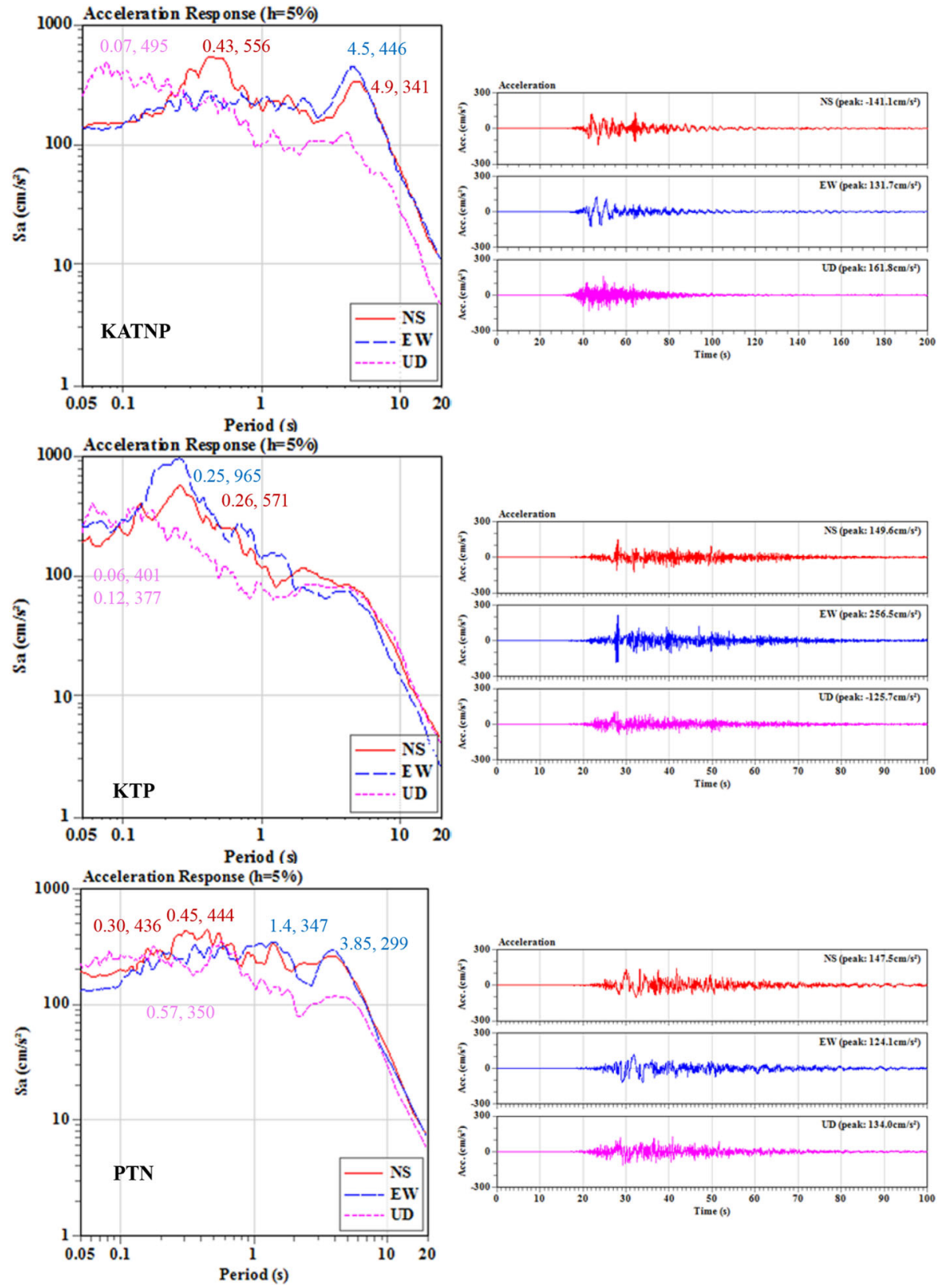

Fig. 4 Corrected acceleration records and spectra analyses of the main shock from KATNP, KTP, PIN, THM and TVU stations. Original records are supplied by USGS (2015 for KATNP) and Takai et al. (2016 for the others)

Intensity Scale and corrected by the observed PGA value at USGS, NEIC, IRIS and CESMD stations in Nepal and India. The error of the estimated acceleration is up to $16.4 \%$ by using the new attenuation formula proposed by Ahmad and Singh (2016). The models 

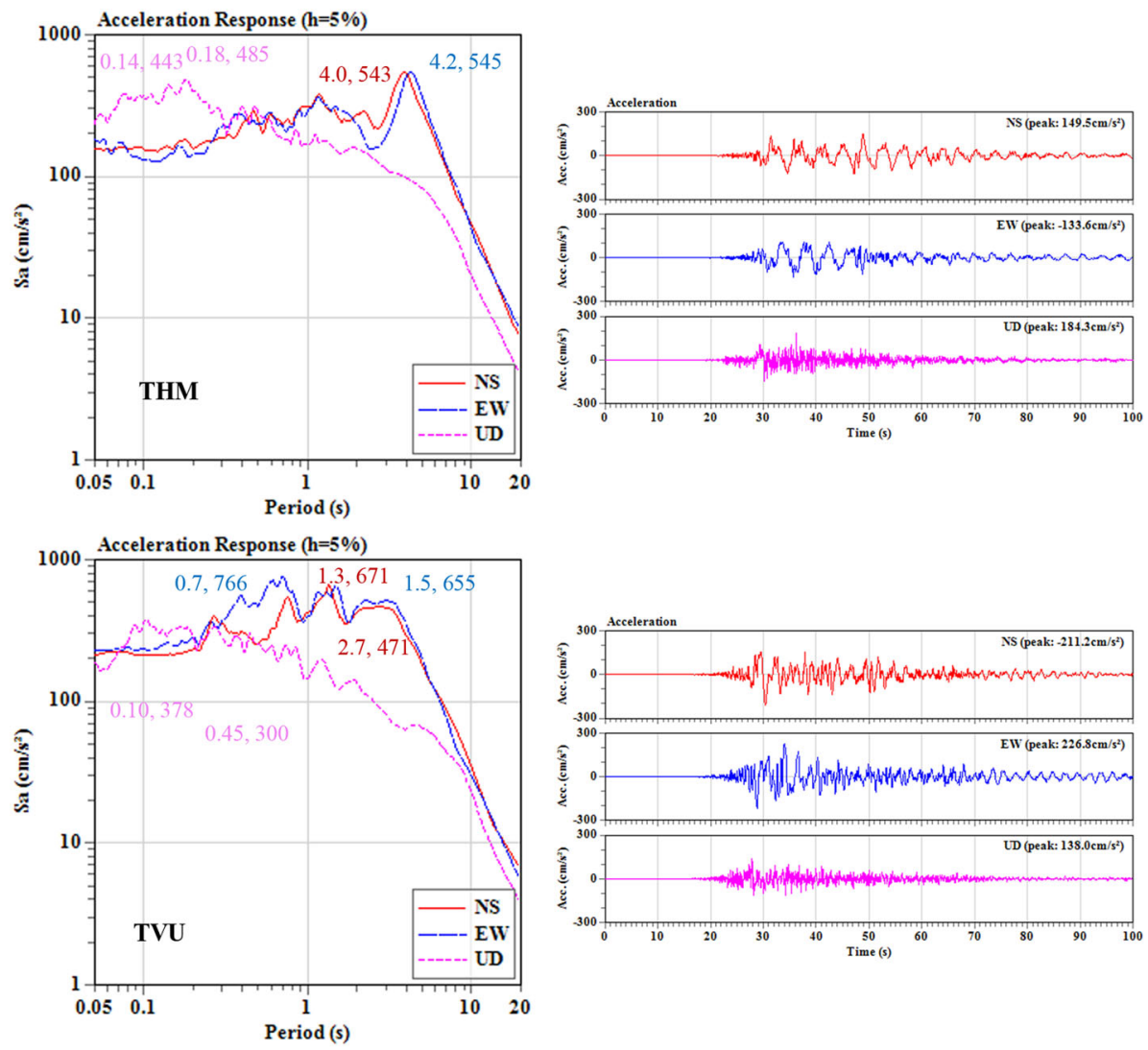

Fig. 4 continued

of Si and Midorikawa (2000) and Ahmad and Singh (2016) are evaluated in Table 3 to make comparison with field study results.

Table 3 also lists the epicentral distance from the main shock, Vs30, altitude, geological information and seismic intensity of each school to be introduced according to Chinese seismic intensity scale. Vs30 is the average shear-wave velocity of the top $30 \mathrm{~m}$, which is often used as an approximate parameter in ground motion models (Wald and Allen 2007). The topographic slope data could be used to estimate the site amplification, which is useful for fast earthquake intensity assessment. It was found that most of the investigated spots located on the site classification C with Vs30 between 620 and $762 \mathrm{~m} / \mathrm{s}$ according to National Earthquake Hazard Reduction Program (NEHRP).

\subsection{Rupture process}

USGS (2015) reports that the strike/dip/rake of the main shock was $290^{\circ} / 7^{\circ} / 101^{\circ}$, respectively. Galetzka et al. (2015) used interferometric synthetic aperture radar data to model the earthquake rupture procedure and found that a $\sim 20 \mathrm{~km}$ width, $\sim 6$ s duration and $1.1 \mathrm{~m} / \mathrm{s}$ peak velocity slip pulse propagated at $\sim 3.3 \mathrm{~km} / \mathrm{s}$ over $140 \mathrm{~km}$ towards Kathmandu. 
Table 2 The seismic records of the Gorkha main shock at KATNP, KTP, PIN, THM and TVU stations

\begin{tabular}{|c|c|c|c|c|c|c|c|c|c|}
\hline \multirow[t]{2}{*}{ Station name } & \multicolumn{2}{|c|}{ Location } & \multicolumn{3}{|c|}{ Epicentral distance $(\mathrm{km})$} & \multirow[t]{2}{*}{ Base } & \multicolumn{3}{|c|}{ Uncorrected acceleration (gal) } \\
\hline & & & & & & & EW & NS & UD \\
\hline KATNP & \multicolumn{2}{|c|}{$84.336^{\circ} \mathrm{E}-27.738^{\circ} \mathrm{N}$} & \multicolumn{3}{|l|}{76.7} & Soil & 136.7 & -141.6 & 161.1 \\
\hline KTP & \multicolumn{2}{|c|}{$85.273^{\circ} \mathrm{E}-27.682^{\circ} \mathrm{N}$} & \multicolumn{3}{|l|}{75.9} & Rock & 254.8 & 153.6 & -126.9 \\
\hline PTN & \multicolumn{2}{|c|}{$85.319^{\circ} \mathrm{E}-27.682^{\circ} \mathrm{N}$} & \multicolumn{3}{|l|}{79.3} & Soil & 128.1 & 150.7 & 133.9 \\
\hline THM & \multicolumn{2}{|c|}{$85.377^{\circ} \mathrm{E}-27.681^{\circ} \mathrm{N}$} & \multicolumn{3}{|l|}{83.7} & Soil & -133.8 & 150.5 & 183.7 \\
\hline TVU & \multicolumn{2}{|c|}{$85.288^{\circ} \mathrm{E}-27.682^{\circ} \mathrm{N}$} & \multicolumn{3}{|l|}{77.0} & Soil & 228.8 & -209.9 & 138.3 \\
\hline \multicolumn{3}{|c|}{ Corrected acceleration (gal) } & \multicolumn{3}{|c|}{ Corrected velocity $(\mathrm{cm} / \mathrm{s})$} & & \multicolumn{3}{|c|}{ Corrected displacement $(\mathrm{cm})$} \\
\hline EW & NS & UD & EW & NS & UD & & EW & NS & UD \\
\hline 131.7 & -141.1 & 161.8 & 81.0 & 66.2 & 35.0 & & -71.7 & -67.8 & -29.5 \\
\hline 256.5 & 149.6 & -125.7 & -27.3 & -30.0 & 30.8 & & 20.7 & -26.3 & 22.5 \\
\hline 124.1 & 147.5 & 134.0 & 56.9 & 61.4 & 40.3 & & 48.3 & -54.0 & 34.8 \\
\hline-133.6 & 149.5 & 184.3 & 73.9 & 62.4 & 45.7 & & -60.1 & 51.5 & -24.0 \\
\hline 226.8 & -211.2 & 138.0 & 74.9 & 101.1 & 34.8 & & -39.5 & -51.7 & 22.6 \\
\hline
\end{tabular}

Feng et al. (2016) found that the largest slip concentres at depths of between 8 and $15 \mathrm{~km}$ with the maximum $6 \mathrm{~m}$ slip at a depth of $10.7 \mathrm{~km}$ by training the best-fit slip distribution model using a layered crustal structure. The total released seismic moment is $7.8 \times 10^{20} \mathrm{~N} \mathrm{~m}$, equivalent to an earthquake of $\mathrm{Mw} \sim 7.84$.

Yagi and Okuwaki (2015) applied a novel waveform inversion formulation and a hybrid back projection method to calculate the seismic rupture process of the main event. It showed that the large-slip event included a rapid rupture acceleration event and a deceleration of the rupture propagation before the rupture terminated. The main shock is estimated to have a slip distribution over $120 \mathrm{~km} \times 80 \mathrm{~km}$. The largest calculated slip was up to $7.43 \mathrm{~m}$ as shown in Fig. 5. In this figure, the strike direction of the main shock and longitudinal directions of two perpendicular RC frames of School No. 3.5 are marked. It is found that the strike direction of the main shock coincides with the direction of the transverse wall of the Building a which has much lighter damage than the longitudinal direction. The forward-directivity effect might be one of the possible reasons for the large differences between the seismic damage intensities of the two perpendicular directions.

\section{Seismic damage to schools with RC frames}

Self-made reinforced concrete (RC) frames are popular in Nepal. Most of the schools we found with RC frames had two to four storeys; they rarely reached five storeys. The construction sequence for this unique structure type is as follows. First, the RC frame is constructed, and the masonry outer wall and infill wall are then constructed. Normally, the column outranges the roof by about half a storey in height for further construction of higher storeys. The vertical load is supported by the RC frame only. The reinforcement ratio is low, partially due to the lack of a developed domestic steel industry. Thus, the intervals between columns cannot be large. During the earthquake, the masonry walls function only 


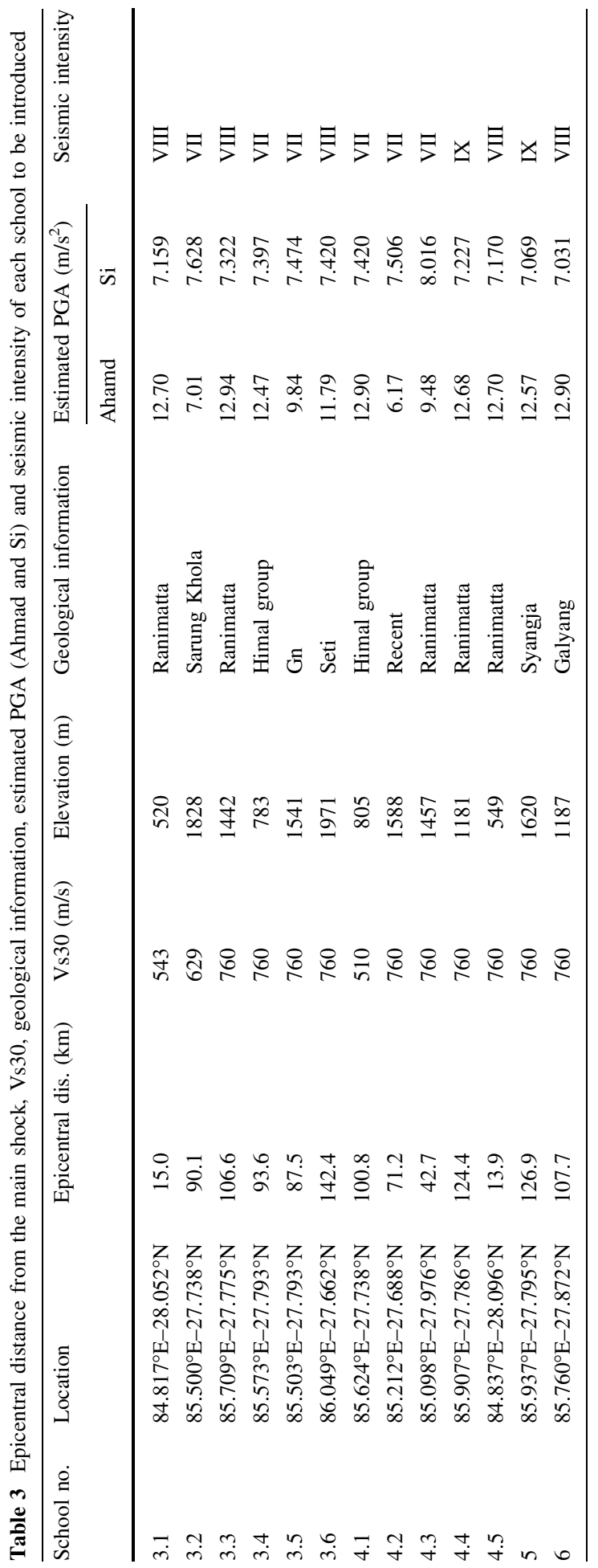




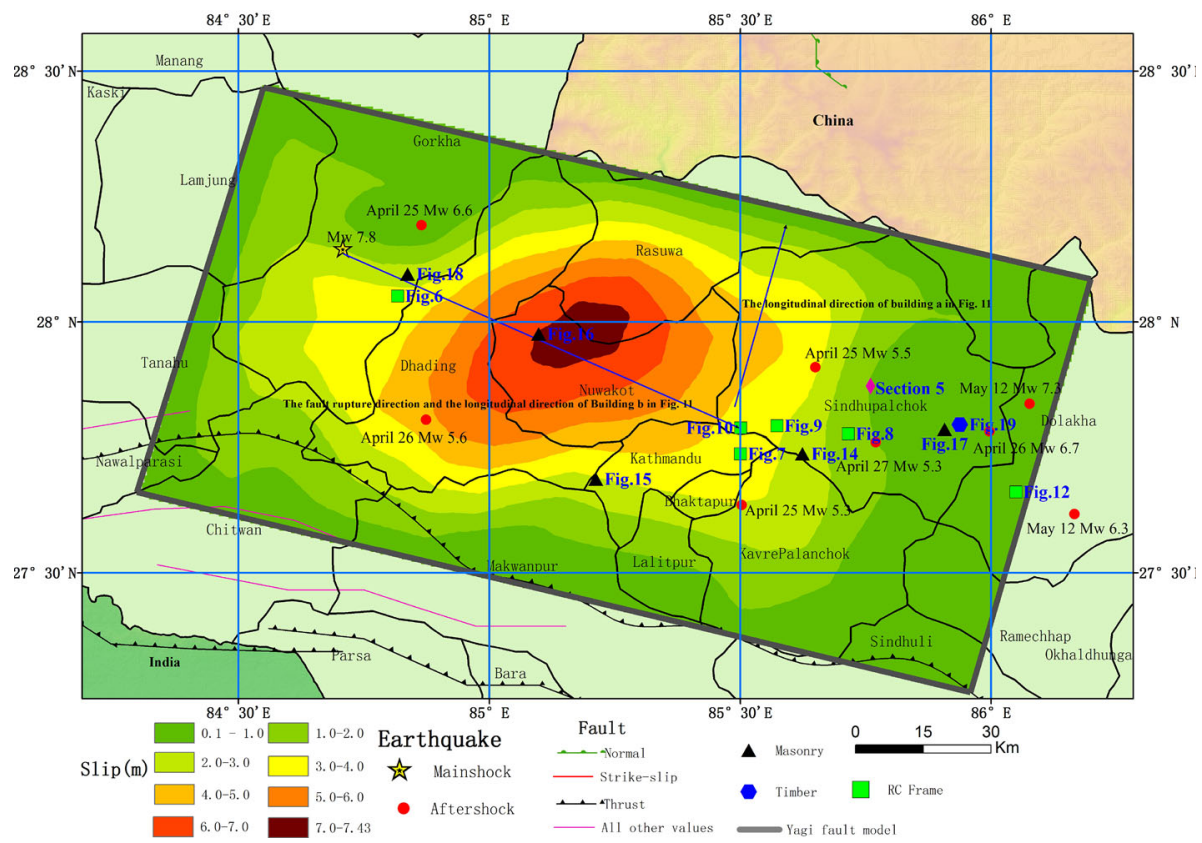

Fig. 5 The accumulated slip distribution of the main shock calculated by Yagi and Okuwaki (2015)

under large deformation, acting as the first line of defence of energy-absorbing components. A detailed description of this structural type is given by Chaulagain et al. (2013). Six schools of RC frames found during our trip will be introduced.

\subsection{Bhimodaya Higher Secondary School}

A university with a three-storey (partial four-storey) RC frame built in August 2012 was found on the large flat lower terrace between the Aarughat road and Buri Gandaki River in the Aruchanaute Gorkha Gandaki district (Fig. 6a). The topography map is captured from Google Earth as shown in Fig. 6b. The structure showed many typical types of damage, such as the short column effect due to the sudden change in the lateral stiffness supplied by the half-height walls in the corridors, $X$ cracks between holes in the masonry walls and the existence of a weak floor (the bottom floor) due to the failure of the 'weak beam/slab, strong column design' in realising the shared energy absorption amongst the structural components of all floors. The masonry wall of the staircase connecting the first and second floors had a severe crack, as shown in Fig. 6c. Based on the state of the seismic damage to the bottom floor, the possibility of collapse if a strong aftershock hit this area was high. Thus, the university was graded as 'dangerous' after inspection by the Nepal government, so it could no longer be used as a refuge until it was repaired.

There were 14 columns along the corridor for each floor with the interval distance around $5 \mathrm{~m}$, marked $\mathrm{A}$ through $\mathrm{N}$ as shown in Fig. 6d. The subscript following the letter indicates the floor to which it belongs, e.g. $\mathrm{A}_{2}$ stands for a column on the second floor, whilst $M_{1}$ stands for the column next to and in the same cross section with $M_{1}$. All of the columns were inspected carefully and are shown in Fig. 6d, e. Column $\mathrm{A}_{1}$ failed due to constraint by the adjacent half-height wall, which induced a shear force and bending 
moment at the column's lower section. The exposed longitudinal reinforcement bar had a diameter of $16 \mathrm{~mm}$ with $\Phi 8 \mathrm{~mm}$ stirrup @ $120 \mathrm{~mm}$. Column $\mathrm{B}_{1}$ suffered less damage, but the upper and lower concrete cover broke off due to the short column effect. Columns $\mathrm{C}_{1}$ through $G_{1}$ were almost intact; damages were found in the corner columns $C_{1}$ and $D_{1}$. However, on the symmetrical side, $\mathrm{H}_{1}$ had moderate damage at its connection to the halfheight masonry wall. The concrete of column $\mathrm{I}_{1}$ was reduced to rubble, leaving its yielded reinforcement bars twisted. $\mathrm{J}_{1}$ and $\mathrm{K}_{1}$ had only slight damage. Column $\mathrm{L}_{1}$ at the inner corner also had severe damage. Columns $\mathrm{M}_{1}$ and $\mathrm{N}_{1}$ had less damage, probably due to the early out-of-plane collapse of the adjacent masonry walls. The inside view of the columns on the first and second floors (Fig. 6f, g) shows the great variation in the seismic damage intensity, which indicates that the structure member of the higher storey did not share

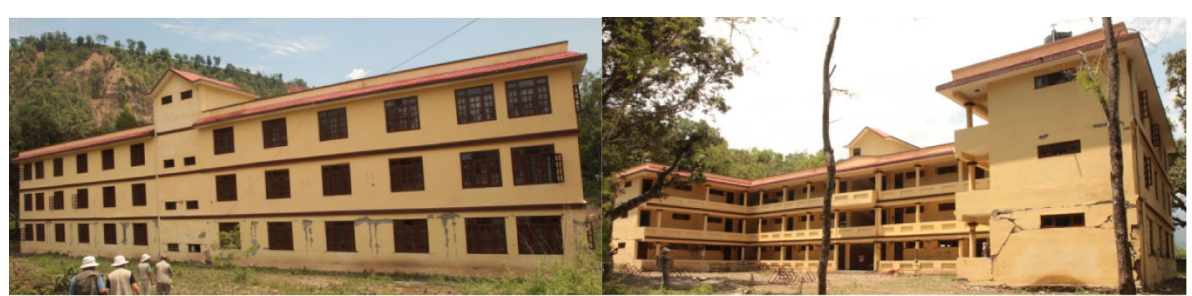

(a)

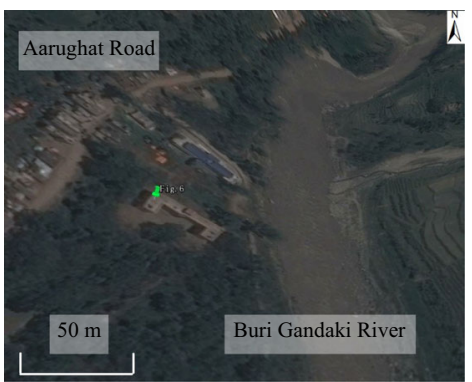

(b)

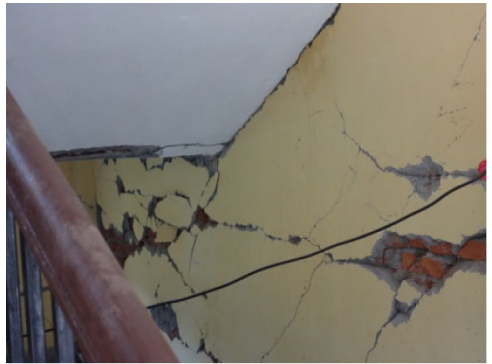

(c)

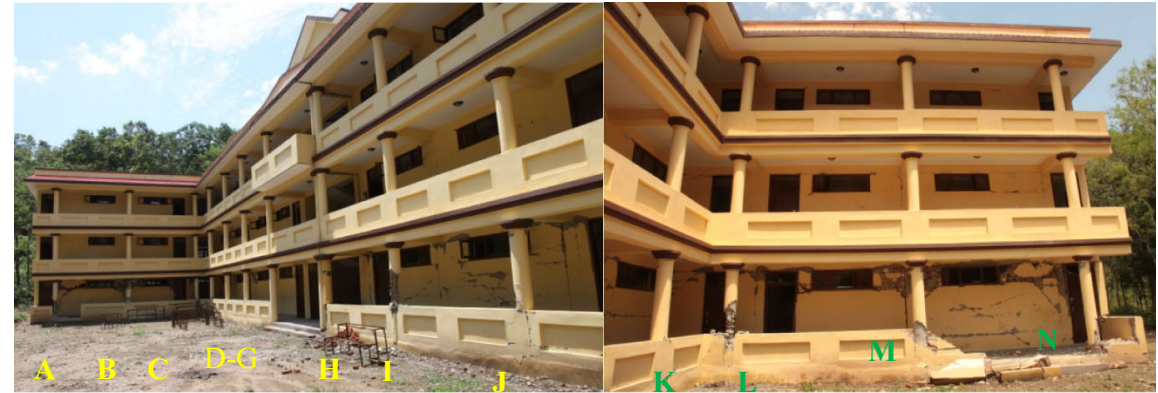

(d)

Fig. 6 Seismic damage to a three-storey university with a reinforced concrete (RC) frame. a Overview (left north elevation; right south elevation). b Nearby topological information. $\mathbf{c}$ Wall of the staircase between first and second floors. d South elevation and damage to 14 columns (A through N) of the corridors on the first floor. e Seismic damage to 11 columns along the corridor of the first floor. $\mathbf{f}$ Inside a classroom on the first floor in the same cross section as column M1. $\mathrm{g}$ Column of a classroom on the second floor in the same cross section with column 12 


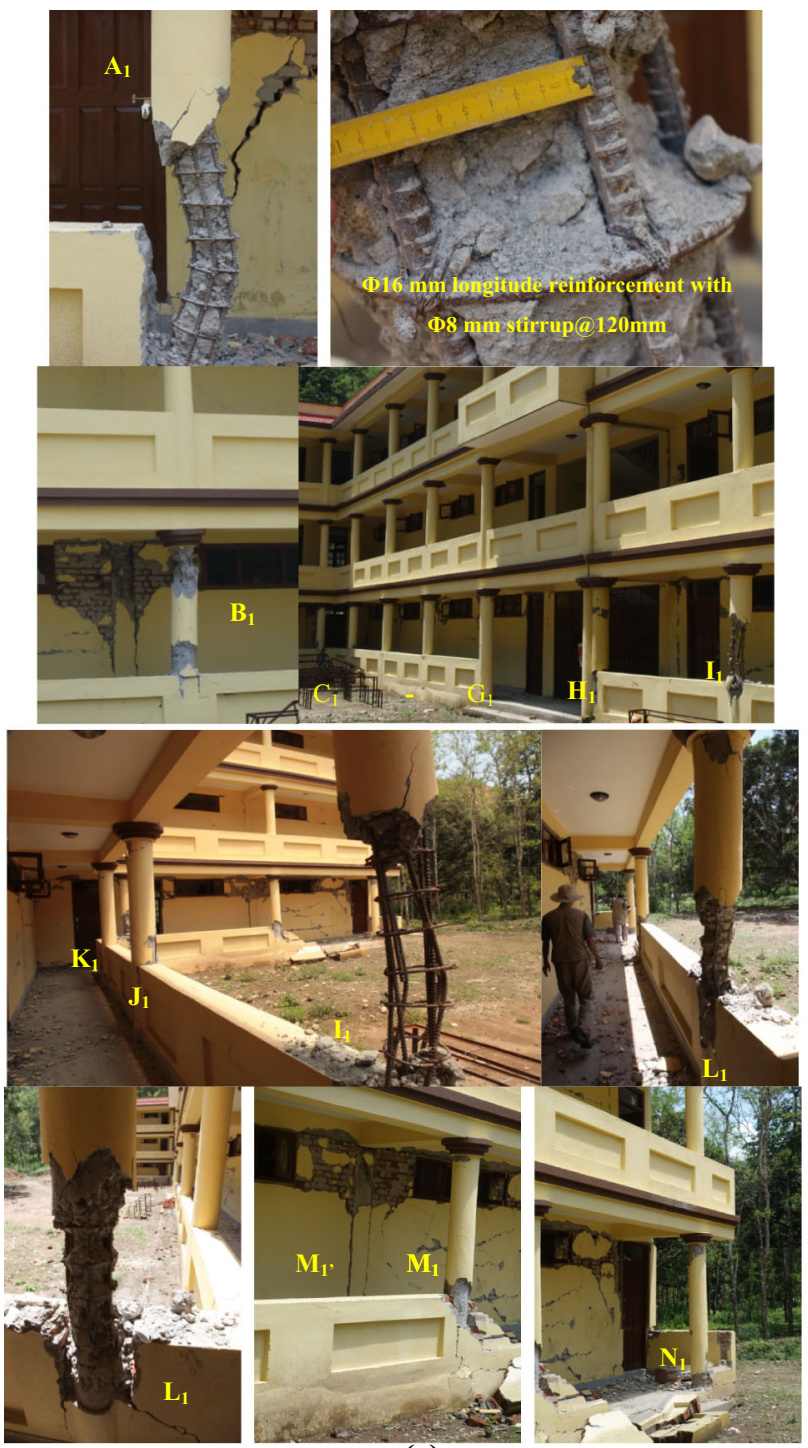

(e)

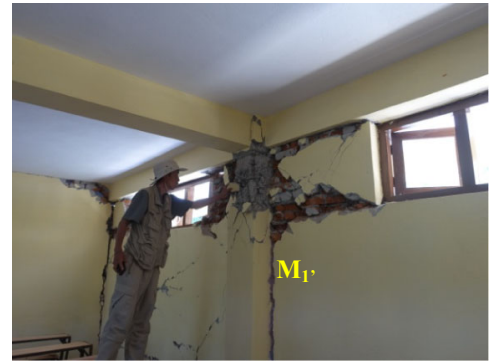

(f)

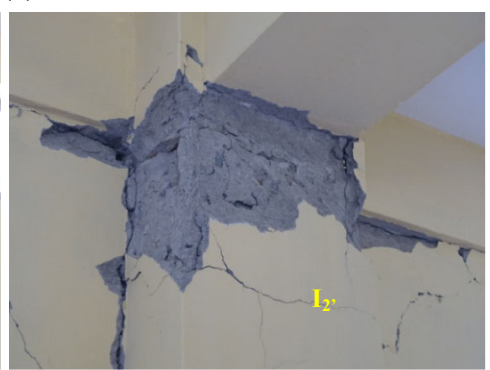

(g)

Fig. 6 continued 
sufficient load and energy dissipation, leading to the first floor becoming the weak floor. The entire structure is symmetrical along the partial fourth-storey central line.

However, the different seismic intensities experienced by columns $F_{1}$ and $G_{1}$ and $H_{1}$ and $I_{1}$ could be due to the local adverse site configuration (the detail site configuration report is not available until now), the live load distribution or the local defect of the columns. It is worth noting that the columns $\mathrm{H}_{1}$ and $\mathrm{I}_{1}$ were closer to the river, and the columns $F_{1}$ and $G_{1}$ were close to the higher terrace (by about $5 \mathrm{~m}$ ) as shown in Fig. $6 \mathrm{~b}$.

\subsection{Shree Bhumeshwory Higher Secondary School, Sindhupalchok}

Located on a small hilltop (estimated to be $40 \mathrm{~m}$ higher than the hill foot; see Fig. 7a-d), this school suffered moderate damage to its stone masonry walls. The masonry walls of the first floor had severe damage, whilst those on the second floor had only slight damage at the joint of the masonry wall and the RC frame, as shown in Fig. $7 \mathrm{~g}-\mathrm{i}$. The outer cement belt net enhanced the wall's bonding strength (Fig. 7a, b, e, f). The out-of-plane collapse of the masonry wall was due to the heavyweight of the rock with the limited bonding strength (Fig. 7c). However, the RC column suffered limited damage (Fig. 7a, b, e). One additional defect is shown in Fig. 7a: there was no column beneath the slab of the first floor near the staircase. Although it did not lead to significant damage to the upper structure due to the lightweight above under moderate seismic input, this situation should be avoided to prevent partial collapse. The staircase was almost intact; cracks were found at the joint of the stair step and the masonry wall supporting it.

\subsection{Shree Bandevi Secondary School}

This three-floor RC frame located at Chautara 8, Sindhupalchok, was constructed with financial assistance from Germany and Austria in November 2012 (Fig. 8a). The connection between the masonry wall and the RC frame at the corner had an apparent crack along the interface of the frame and the masonry wall, as shown in the lower left panel of Fig. 8a. The small water tank on the roof of a nearby bungalow (Fig. 8f shows relative positions of the two buildings) had moved about $17 \mathrm{~cm}$, as measured from the stamp shown in the lower middle panel of Fig. 8a. The inner masonry walls of the first floor between the holes (window or door) had developed slight or moderate diagonal cracks (Fig. 8b, c). The wall and the ladder of the staircase connecting the first and second floors had moderate cracks, as shown in Fig. 8d. The damage to the seismic joint is circled in Fig. 8e. The sharp turn of the crack path might indicate the reinforcement configuration or the position of the slab connection (left panel in Fig. 8e). After inspection, the structure could have been graded as moderately damaged in our opinion; however, it was classified as uninhabitable (red sign for danger shown in Fig. 8a) by the Nepal government to prevent the casualties that could result from a collapse.

\subsection{Shree Jalapadevi Higher Secondary School}

This school, located at Melamchi Municipality-8, Bansbari, Bahunipati, Sindhupalchok, had a regular design, as shown in Figs. 9 and 10. Damage was found only in the masonry walls of the first floor and the landing of the staircase connecting the first and second floors. It was interesting to find that the back side of the structure had no apparent damage. Only the front side of the masonry wall showed severe cracking (Fig. 9a), possibly because of 


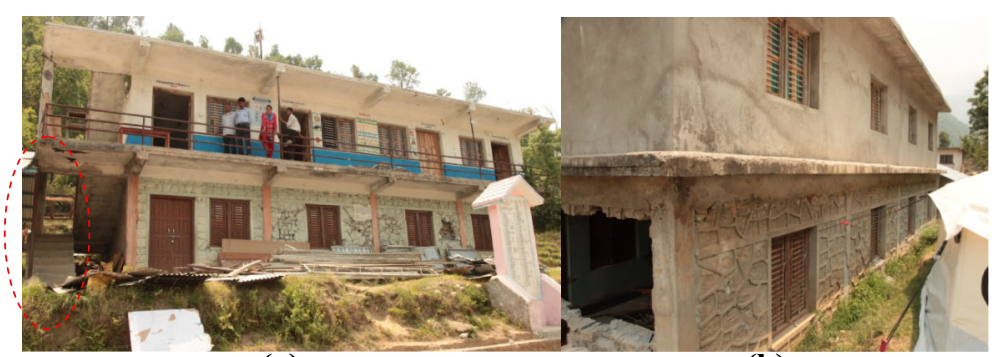

(a)

(b)



(c)

(d)

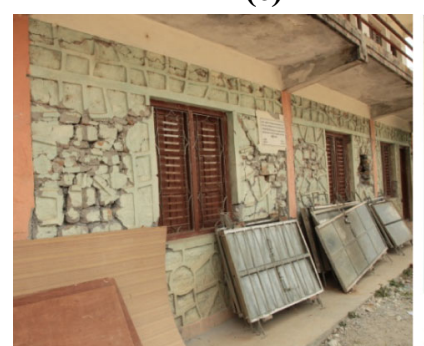

(e)



(f)

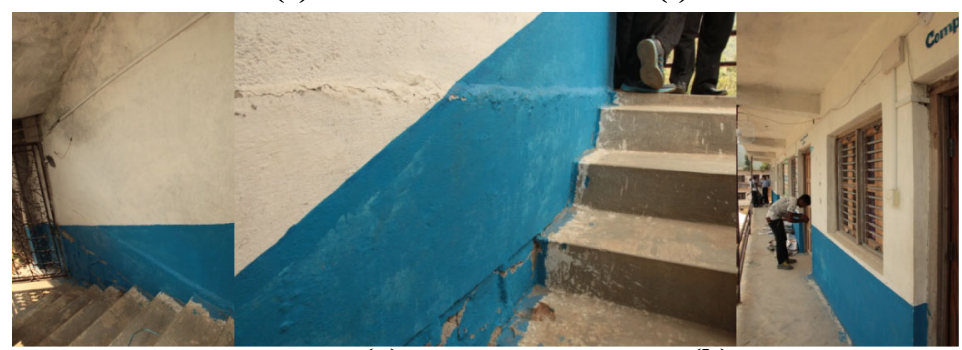

(g)

(h)

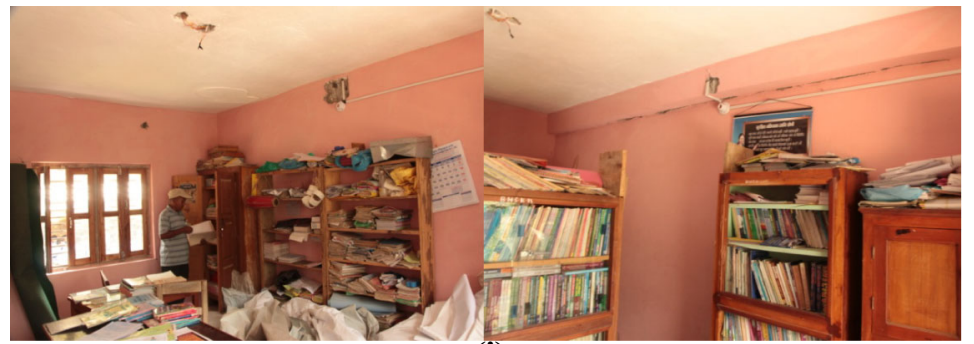

(i) 
4Fig. 7 Seismic damage to Shree Bhumeshwory Higher Secondary School, Muktitar, Sindhupalchok. a South elevation (note the absence of the column underneath). b North elevation. c East elevation. d West elevation. f Crack in the masonry outer wall. g Inside view from the east elevation collapsed wall. h Staircase. i South face of the second floor. j Second floor inside view, slightly damaged (no apparent cracks)

the differing lengths of the holes in the front and back elevations. On the back side, many windows divided the masonry wall into small pieces, thus reducing the in-plane stiffness, whilst the front wall had a longer cross section, which made it stiffer and resulted in more severe damage than that seen on the back side.

\subsection{Shree Saraswati Higher Secondary School (SSHS School)}

The characteristic of this school that distinguishes it from the others is that the seismic damage intensity of the school building differed greatly along the main shock's strike direction and the perpendicular direction. The school located at a small hill with around $10 \mathrm{~m}$ attitude difference from the hill foot (Fig. 10f). The amplification effect due to higher altitude is well known and verified by comparing with surrounding buildings shown in Fig. 10e, f. The nearby house with red circle is almost intact with visible crack perpendicular to the strike direction of the main shock. Another two floor masonry house on a hill has much severer damages.

There are two similar buildings in this school (Fig. 10b, d). For convenience, the smaller building is labelled a and the other b, as shown in Fig. 10a. It was told that these two buildings were built in different years with different construction quality. Thus, it is not objective to compare between these two buildings.

To better study the failure mechanics, the engineering drawings are presented in Fig. 11. Note that the first floor of Building $b$ has the same ichnography as the ground floor, except that the horizontal cut section of the first floor had double runs of staircases. The masonry walls are all $23 \mathrm{~cm}$ thick (standard baked-brick length in Nepal) for both buildings.

The early built Building a has much severe damages along the longitudinal direction, even though there are also many holes in the transverse direction as shown in Fig. 10b, c. It is interesting to find that the transverse direction of Building a coincides with the strike direction of the main shock. One possible reason could be the forward-directivity effect of the input seismic wave. The forward-directivity effect is generated when the velocity of fault rupture is close to the shear-wave propagation velocity. As the rupture front propagates from the hypocenter, the amplitude and the energy of a shear-wave front are accumulated by the shear waves travelling ahead of the rupture front. When a site is located along the fault and the earthquake wave propagates towards the site, the arrival wave front is seen to have a large pulse of motion (a shock wave effect) (Bray and Rodriguez-Marek 2004). Two rupture directivity effects are well known: a change in the magnitude of shaking and the difference in the magnitude of shaking on the two horizontal components oriented perpendicular (larger) and parallel (smaller) to the strike of the fault (Abrahamson 2000).

This proposal is further verified by the inspecting result of Building $b$, which is perpendicular to Building a. It is found that the longitudinal outer walls of the first floor of Building $b$ do not even have visible cracks; only the wall on the platform of the staircase connecting the first and second floors has a minor crack in the transverse direction (the 


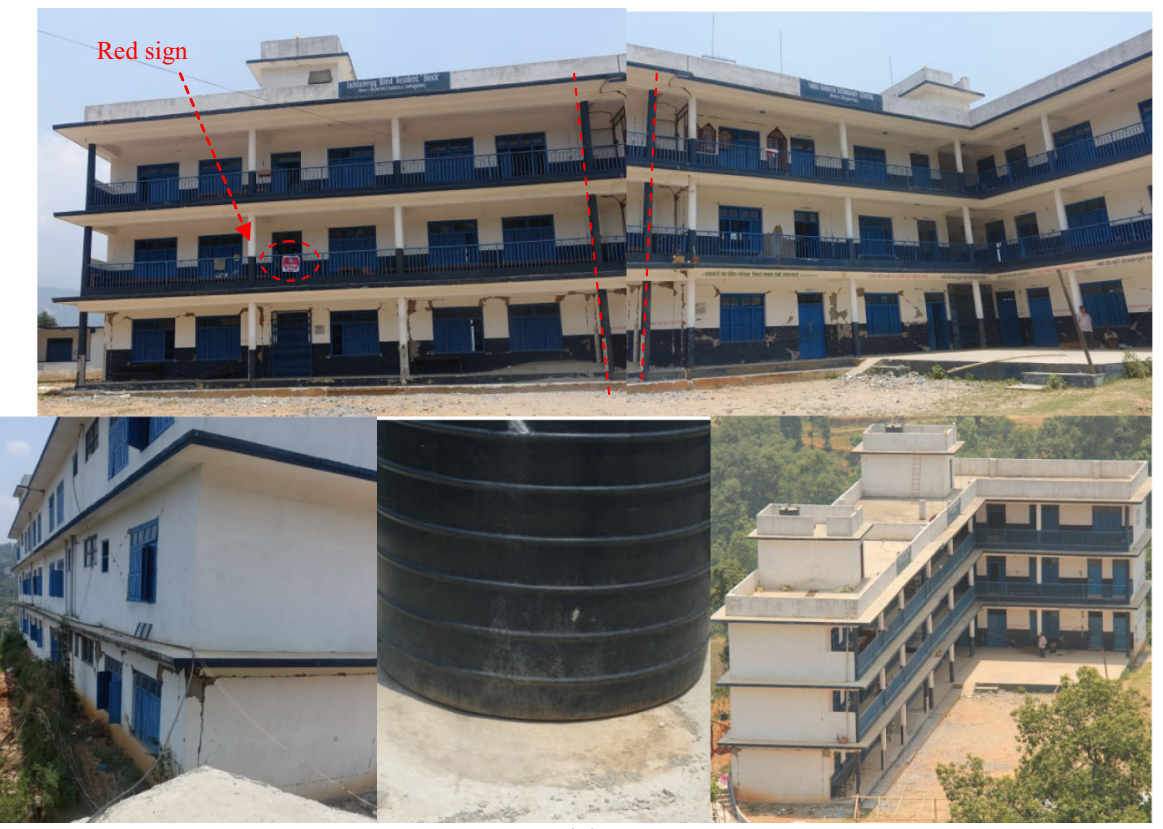

(a)
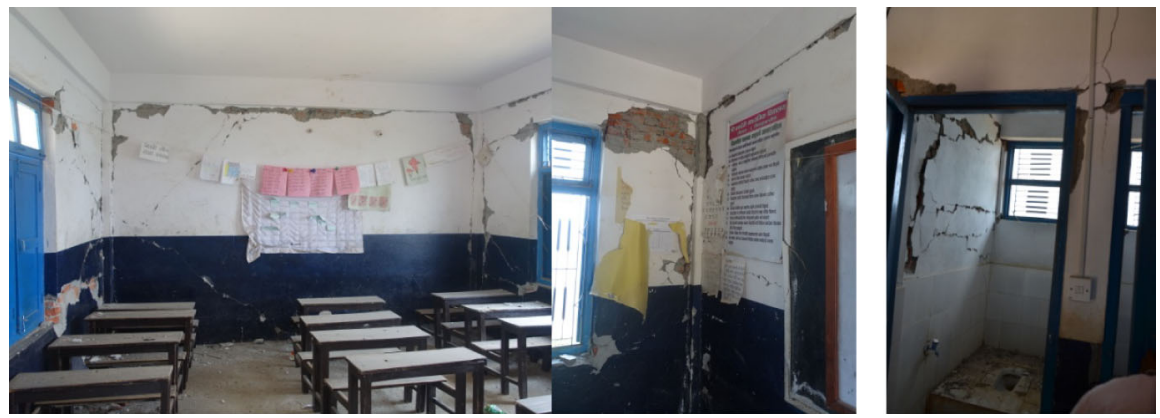

(b)

(c)

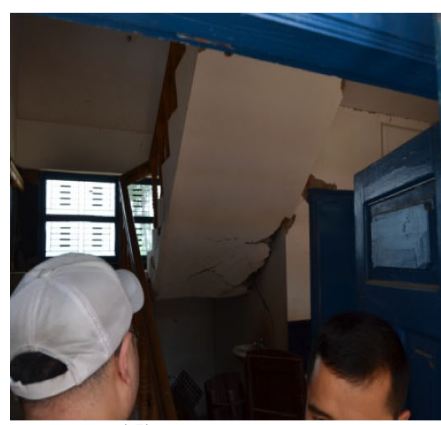

(d)

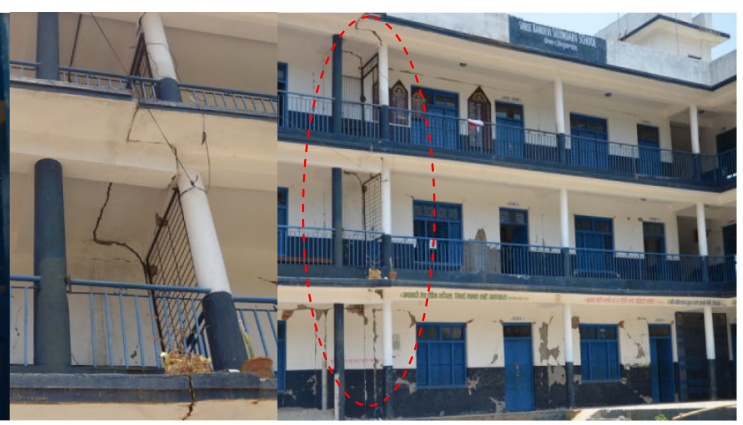

(e)

Fig. 8 Seismic damage to Shree Bandevi Secondary School. a Overview (upper panels are connected at red dashed lines). $\mathbf{b}$ The inner wall had light to moderate damage. $\mathbf{c}$ Crack between the window hole and the toilet door on the first floor. d Severe damages to the staircase connecting the first and second floor. e Large relative movement at the seismic joint. $\mathbf{f}$ The topographic map from the Google Earth 




(f)

Fig. 8 continued

bottom right panel of Fig. 10d), which is the same direction with the severely damaged longitudinal walls of Building a.

Figure 12 and Table 4 show that the epicentres of five earthquakes larger than Mw 6.3 were almost in one line and coincide with the transverse direction of Building a. It could be proposed that the incoming shear waves affected Building a in the longitudinal direction and Building $\mathrm{b}$ in the transverse direction.

This proposal should be further verified by careful study of the fault mechanics and rupture process of the main shock (Yagi and Okuwaki 2015; Grandin et al. 2015; Fan and Shearer 2015) and the large aftershocks (Feng et al. 2016), simulating the wave propagation and determining the vulnerable direction of seismic input for these two buildings (there are no codes in Nepal to deal with the weak seismic input direction right now). However, sufficient analysis of the rupture process of the destructive aftershocks has not yet been conducted. A detailed analysis of the phenomenon requires comprehensive information regarding all destructive input seismic waves. Thus, this work is postponed until all preconditions are met.

\subsection{Rising Star School in Charikot shows the significant role of site configuration on the intensity of seismic damage}

Rising Star School was a five-storey RC frame at Charikot as shown in Fig. 13. No severe damage was found in this building; only minor cracks were observed at the joint between the RC frame and the masonry wall on the first floor. However, only $100 \mathrm{~m}$ from this location, five collapsed and severely damaged similar RC frames were found within an area of $100 \times 50 \mathrm{~m}$ (Fig. 13c). It was told by the local residents that the main shock only damaged most of the buildings. However, the aftershock on May 12 completely destroyed the damaged building as shown in Fig. 13. The reason for this big difference could be the 


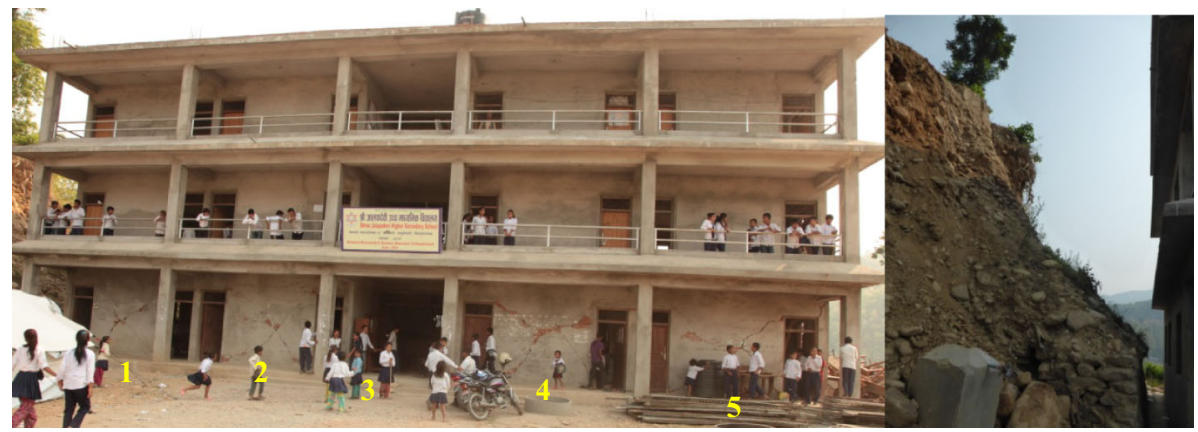

(a)

(b)

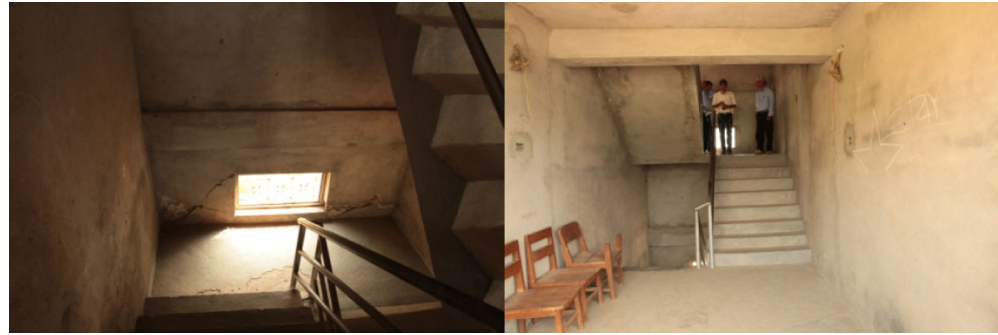

(c)

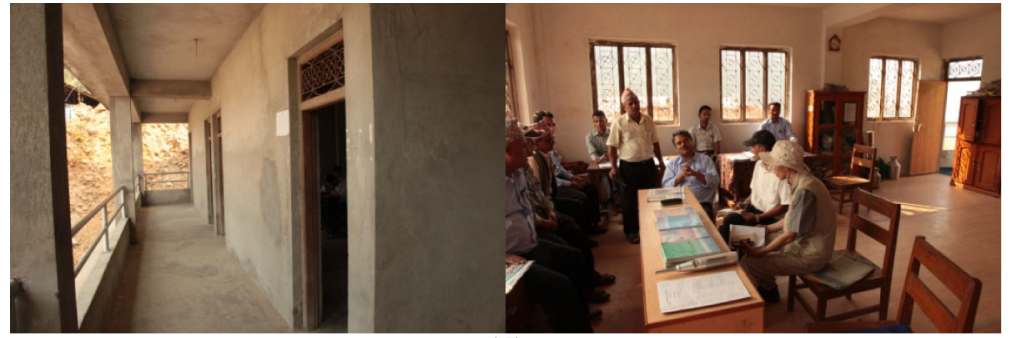

(d)

Fig. 9 Seismic damage to Shree Jalapadevi Secondary School. a Overview. b Hill to the left of the building. c A small crack developed diagonally at the corner of the windows in the staircase connecting the first and second floors. d No damage was observed on the second floor

characteristics of the site configuration. The school is located on relatively flat ground, whilst the collapsed or severely damaged RC frames were located on a suddenly raised divide. The narrow divide might have amplified the long-period component of the seismic input due to its slender shape, which was probably close to the natural period of the RC frame, thus resulting in severe damage. In addition, the foundations of the RC frames on the narrow divide were bounded asymmetrically due to the limited land. Most of the collapsed buildings climbed up a cliff or stood narrowly from the cliff edge. The unequal swing forces during the load cycling of the earthquake tended to push the RC frames into the weaker bounding direction, causing a great amount of tilt or even collapse. 


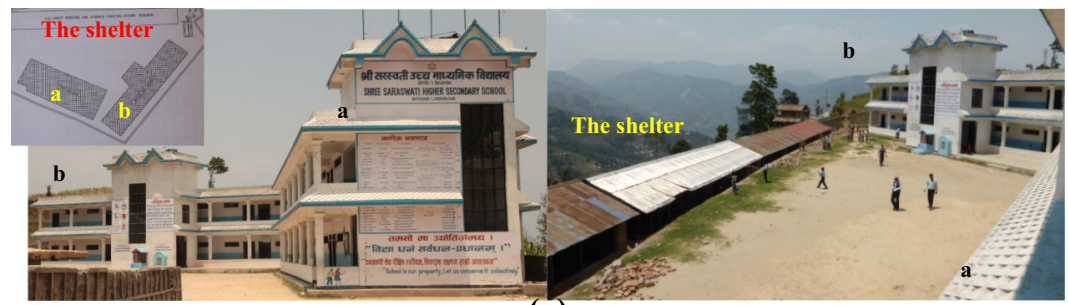

(a)
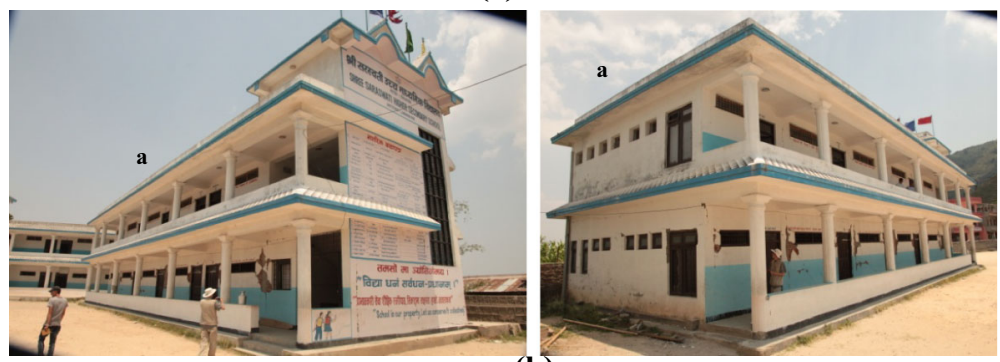

(b)

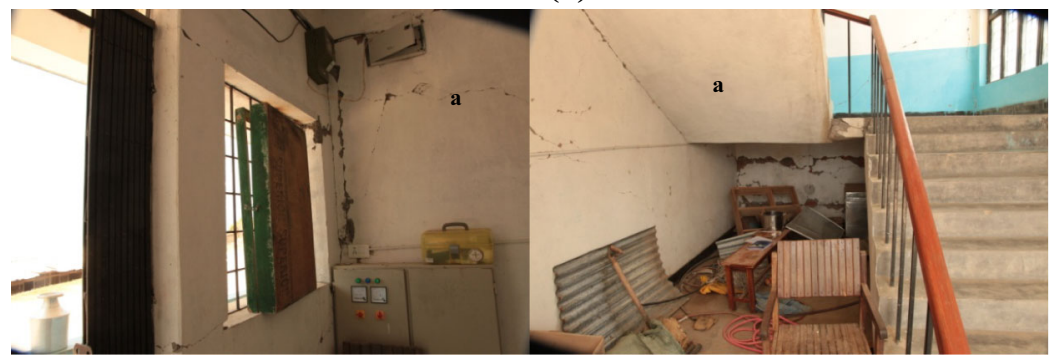

(c)

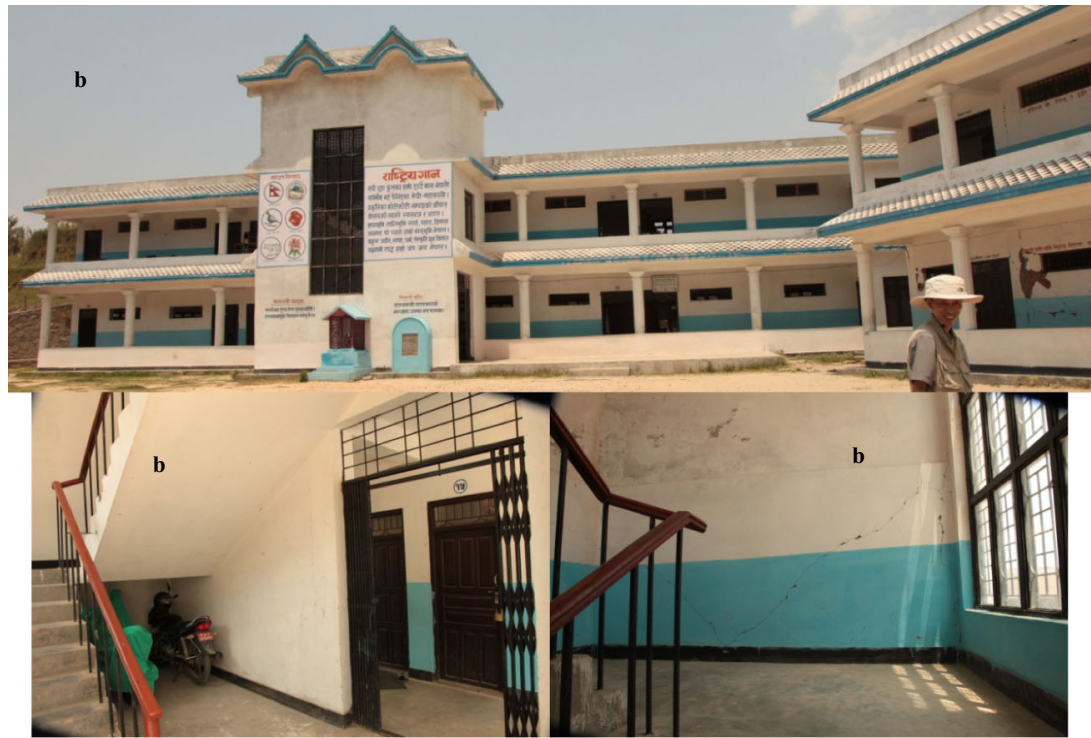

(d) 
4Fig. 10 Seismic damage to Shree Saraswati Higher Secondary School. a Overview. b Cracks were found at the corner of the door and window holes on the first floor of Building a. c Damage to the staircase connecting the first and second floors of Building a. d Limited damage was found in the staircase of Building $\mathbf{b}$. e View along the longitudinal axis of and from Building a to the entrance. $\mathbf{f}$ Details of the circled building in $\mathbf{e}$

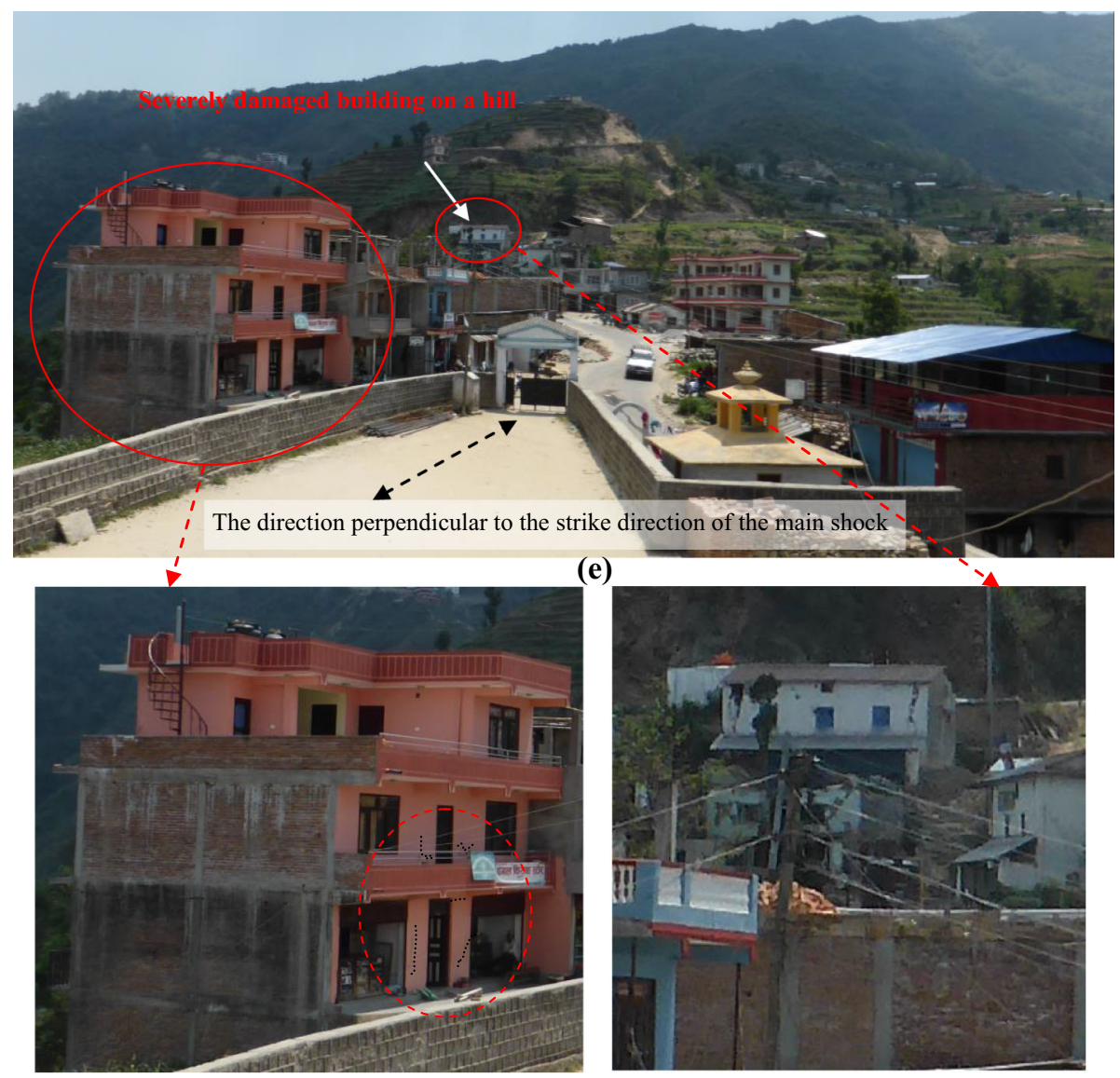

(f)

Fig. 10 continued

\section{Seismic damage to masonry schools}

Masonry is the most popular type of structure, especially in deep mountainous areas (NPHC 2011). Mud-bonded and cement-bonded masonry makes up 41.38 and $28.74 \%$ of the outer wall and 44.21 and $17.57 \%$ of the foundation, respectively. Light roofs, such as galvanised iron $(28.26 \%)$ and straw/thatch $(19.03 \%)$, are normally preferred. Wood and planks are also popular in school masonry construction, especially for the simple temporary frames set up after the earthquake to prevent further causalities subjected to potential aftershocks. Five schools of either mud-bonded or cement-bonded masonry were investigated. In general, the cement-bonded masonry had much better performance than mud- 
bonded masonry. The collapse rate was $36.18 \%$ for mud-bonded masonry and $7.19 \%$ for cement-bonded masonry structures over an area of $168,290 \mathrm{~km}^{2}$ in and around the Rasuwa and Sindhupalchok districts. Most of the school masonry structures were bungalows or two-storey buildings. No taller masonry school buildings were observed along our trip.

\subsection{Popakar Elementary School}

The small Popakar Elementary School had only 150 students and nine teachers and was located at Necpance, Bhimtar, Sindhupalchok. It included one cement-bonded masonry building with a steel-framed corrugated galvanised iron (CGI) sheet roof and one RC frame
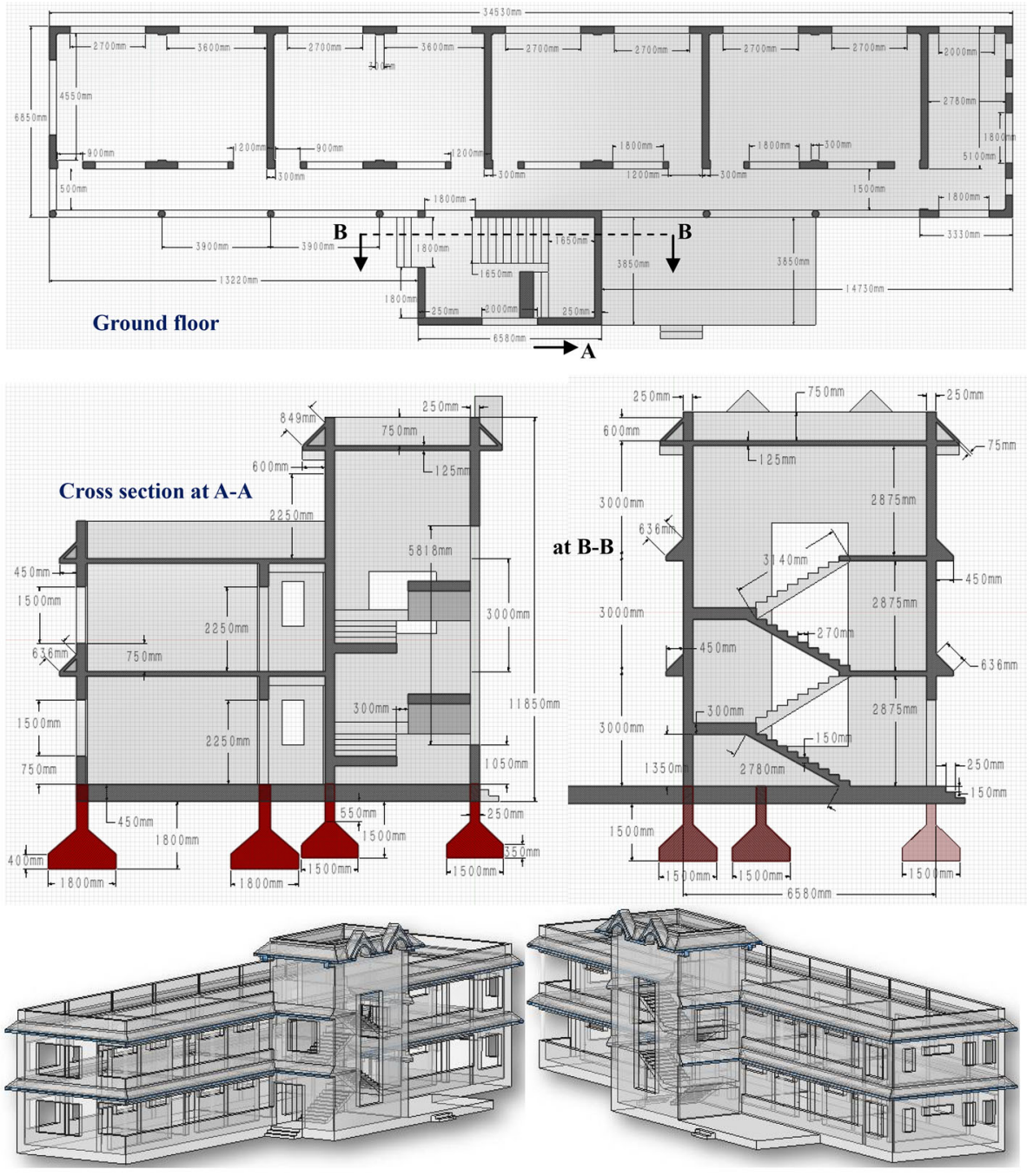

(a)

Fig. 11 Structural engineering drawings of two RC frames in Shree Saraswati Higher Secondary School. a Building $\mathbf{b}$. b Building a 

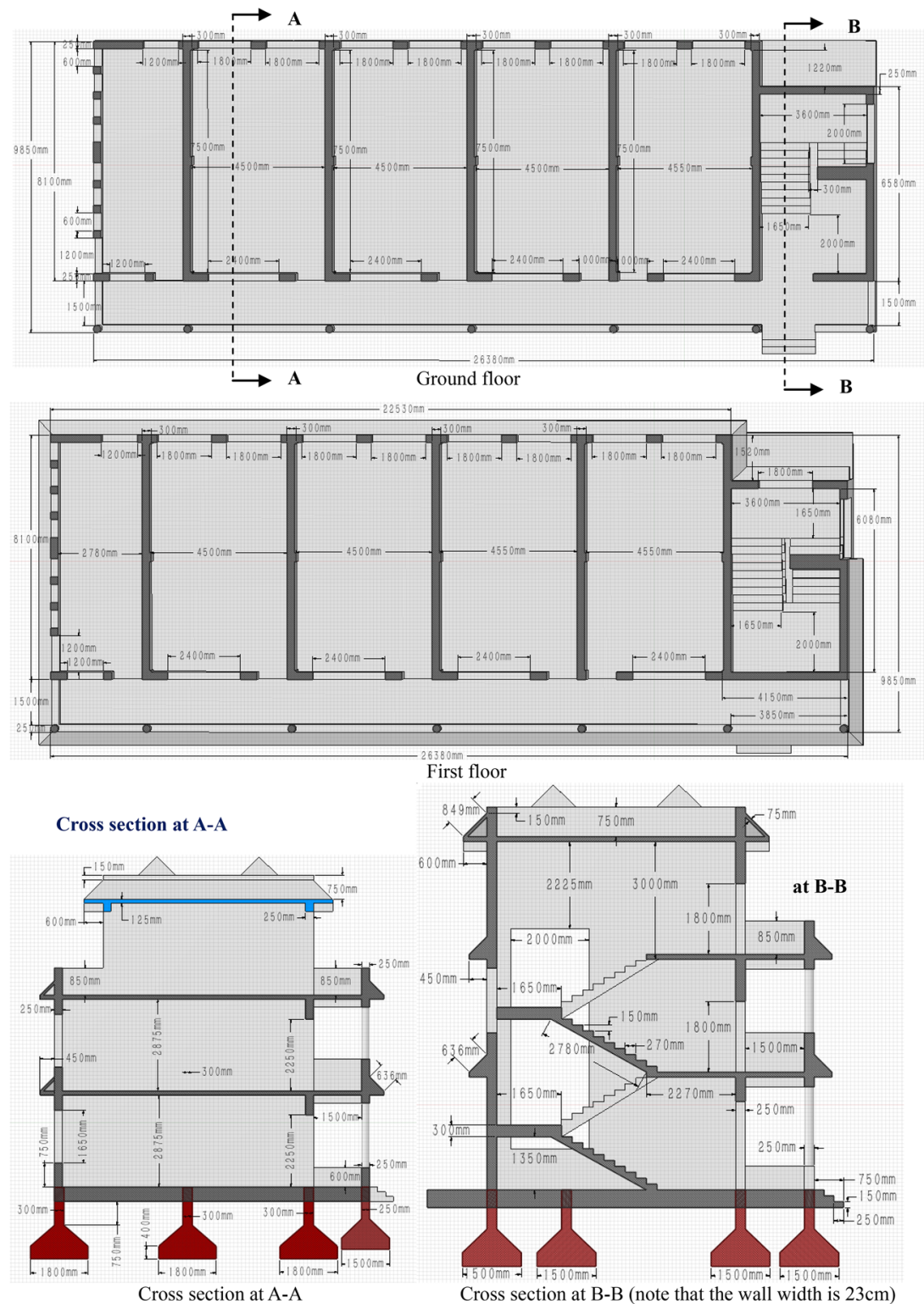

Cross section at A-A
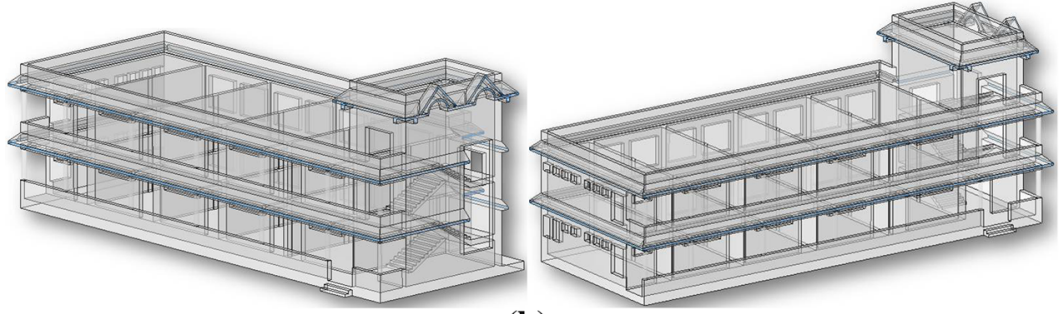

(b)

Fig. 11 continued 


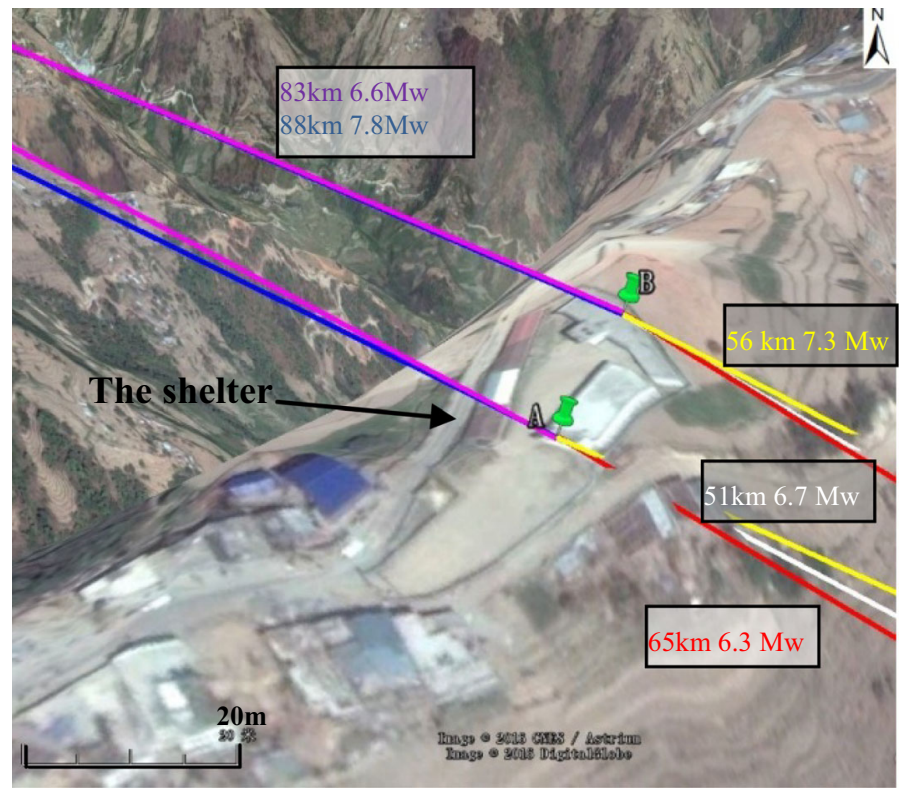

Fig. 12 Geological relationship between the school and major earthquakes larger than Mw 6.3 up to 20 June (Google Earth)

Table 4 Distance between the school and the five largest earthquakes up to 20 June

\begin{tabular}{lllll}
\hline Mw & Date/time UTC & Epicentre & SSHS school & Distance $(\mathrm{km})$ \\
\hline 7.8 & $4 / 25,14: 11: 26$ & $84.708^{\circ} \mathrm{E}-28.147^{\circ} \mathrm{N}$ & $85.5^{\circ} \mathrm{E}-27.78861^{\circ} \mathrm{N}$ & 88 \\
6.6 & $4 / 25,14: 45: 21$ & $84.822^{\circ} \mathrm{E}-28.224^{\circ} \mathrm{N}$ & & 83 \\
6.7 & $4 / 26,15: 09: 00$ & $86.017^{\circ} \mathrm{E}-27.771^{\circ} \mathrm{N}$ & 51 \\
7.3 & $5 / 12,7: 05: 20$ & $86.070^{\circ} \mathrm{E}-27.803^{\circ} \mathrm{N}$ & 56 \\
6.3 & $5 / 12,7: 36: 54$ & $86.162^{\circ} \mathrm{E}-27.625^{\circ} \mathrm{N}$ & & 65 \\
\hline
\end{tabular}

bungalow with an RC roof. The former had severe cracks in the masonry walls (Fig. 14a), whilst the latter was almost intact (Fig. 14b). The reason for the greater damage intensity of the former could have resulted from the lower constraint at the top of the wall because no ring beam or slab was present there and the light steel frame roof could neither provide sufficient stiffness to constrain the out-of-plane movement of the masonry walls nor coordinate the structure to resist the seismic load as a entirety. Thus, localised damage appeared, as shown in Fig. 14a.

\subsection{Thankot Chundevi Secondary School}

Another school located in Bagmati Kathmandu Thankot had a similar structure. The school consisted of six buildings, including a two-storey RC frame (block B) with a masonry wall, two cement-bonded masonry buildings with RC roofs (blocks $\mathrm{C}$ and $\mathrm{E}$ ) and two cementbonded masonry buildings with light steel frame roofs (blocks A, D and F). The overall 


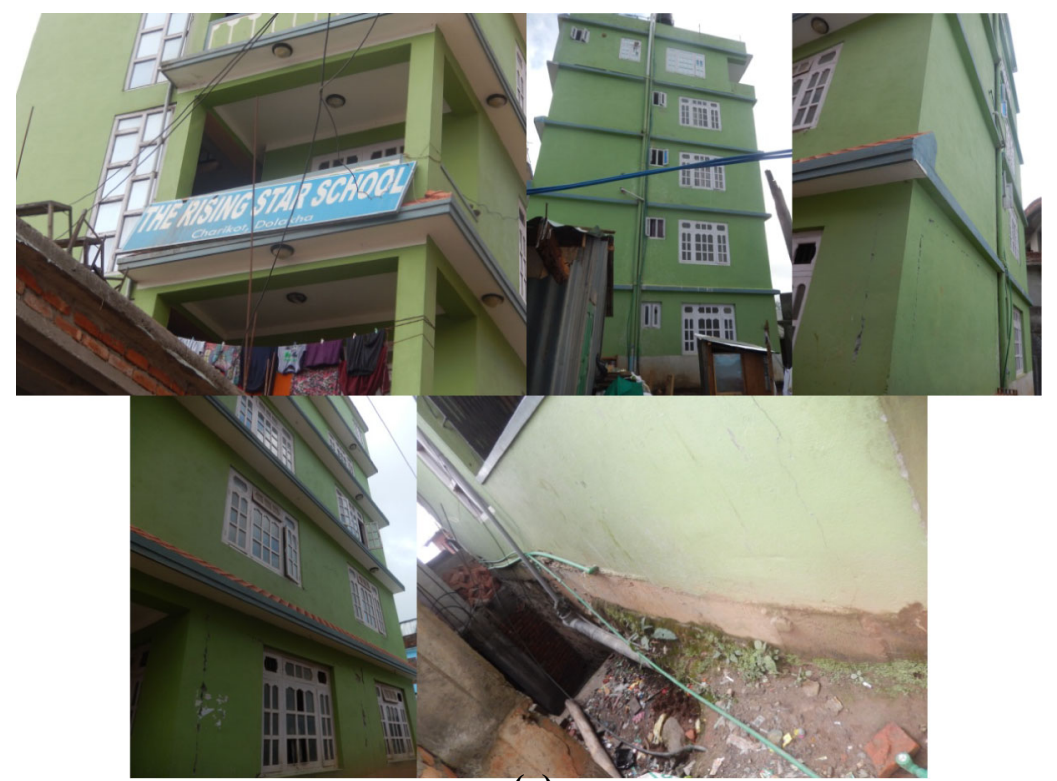

(a)

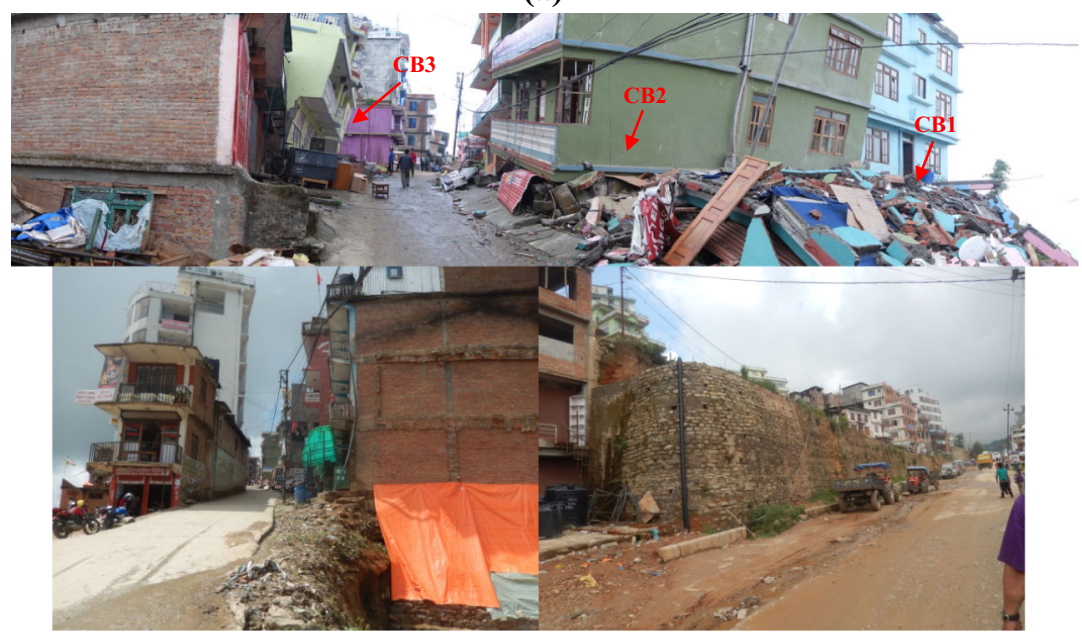

(b)

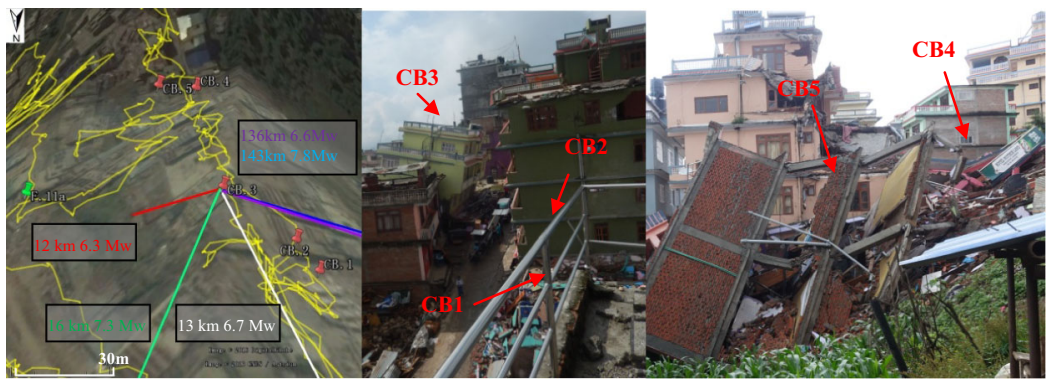

(c) 
४Fig. 13 Seismic damage intensity differed greatly between different RC frames in close proximity, one on flat ground and the others located on a suddenly raised narrow divide. a The school is on relatively flat ground and suffered minor damage. b Assembly of collapsed RC frames nearby, located on a suddenly raised narrow divide ( $\mathrm{CB}$ indicates collapsed buildings on the ridge of the narrow divide). $\mathbf{c}$ The relative positions of these two locations and geological information around the two sites

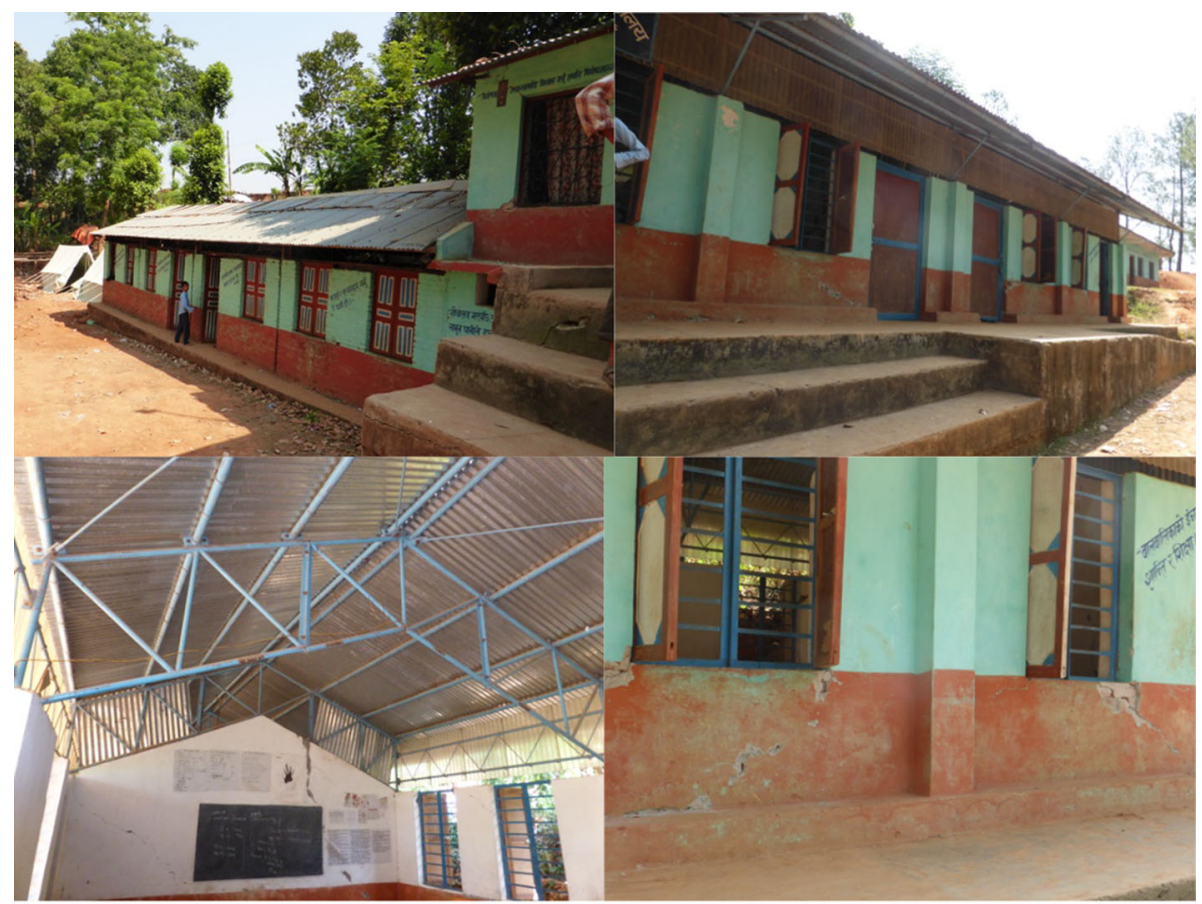

(a)

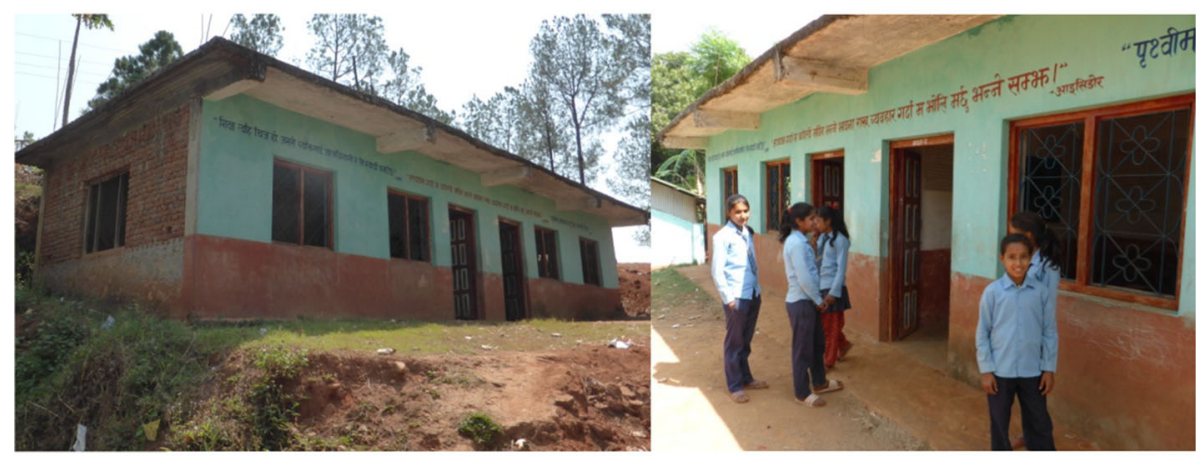

(b)

Fig. 14 Seismic damage to Popakar Elementary School, including one RC bungalow and one masonry structure. a The masonry structure with a light steel frame roof has an apparent crack next to the window and door holes and inside walls. b The RC frame bungalow suffered no damage 


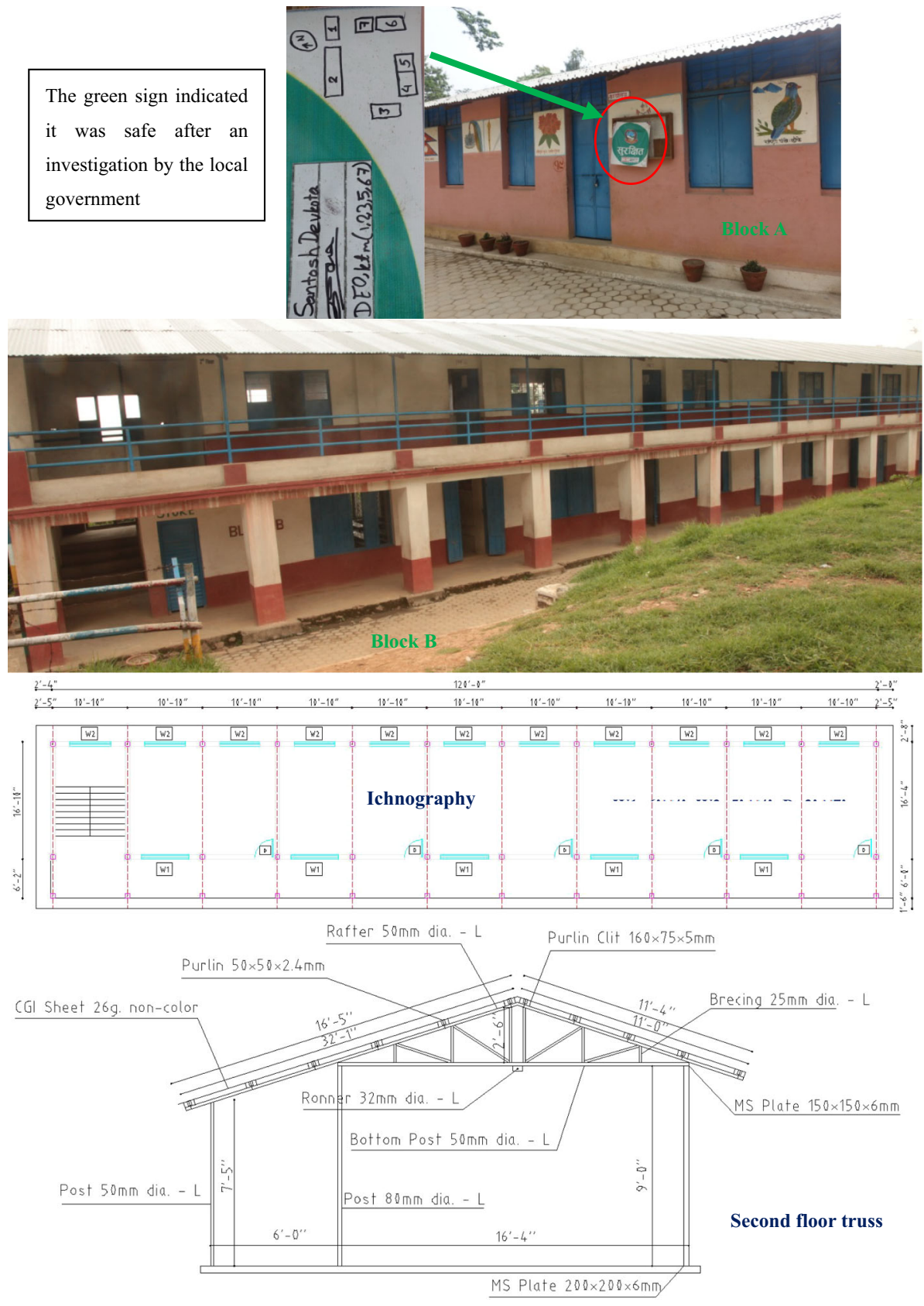

Fig. 15 Seismic damage to one RC bungalow and one masonry structure at Thankot Chundevi Secondary School

seismic damage intensity was low; however, like the damage at Popakar Elementary School, the masonry building with the light steel frame roof had the worst damage, followed by the two-storey RC frame with the masonry wall. The RC bungalow with the RC 

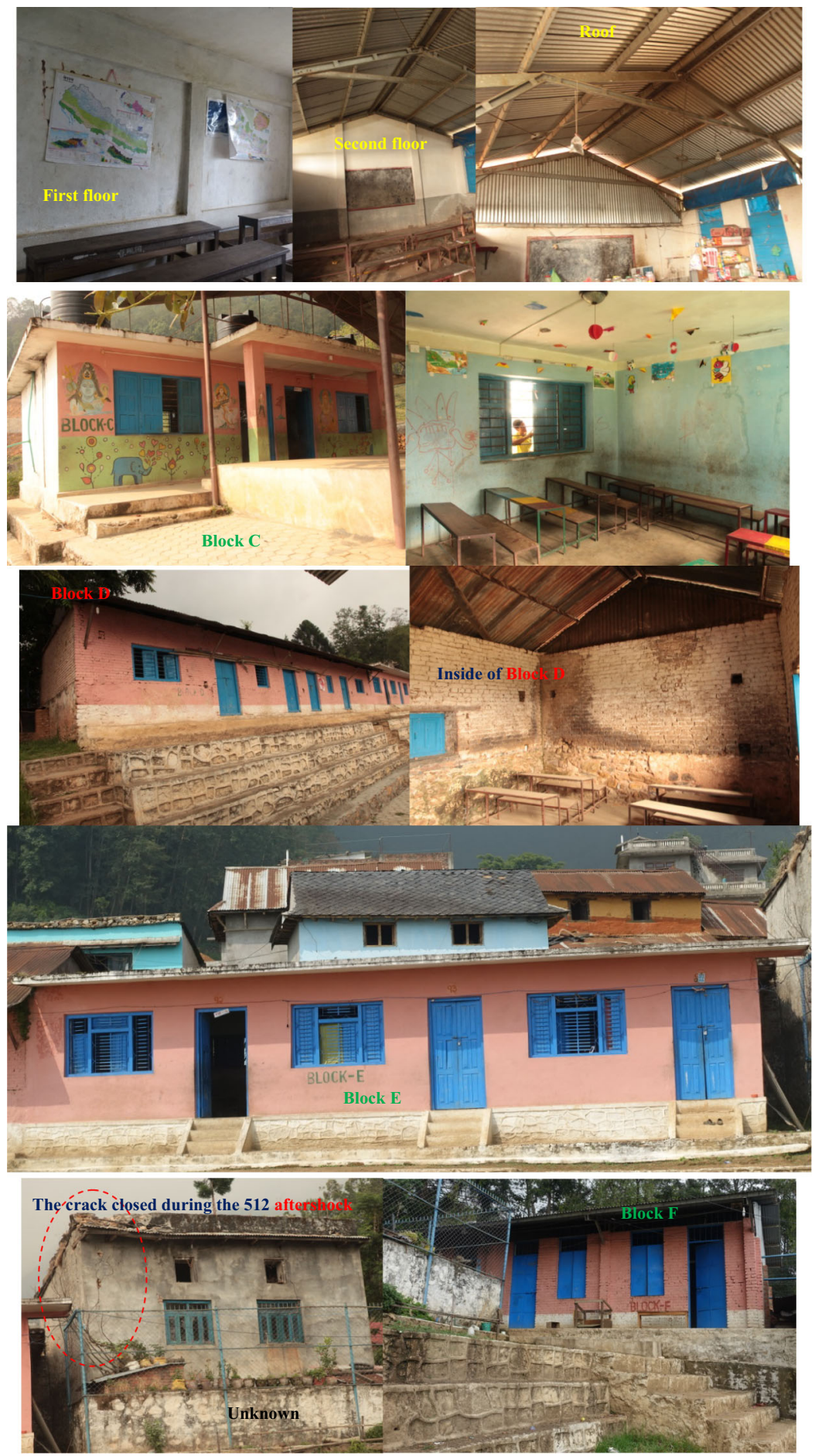

Fig. 15 continued 


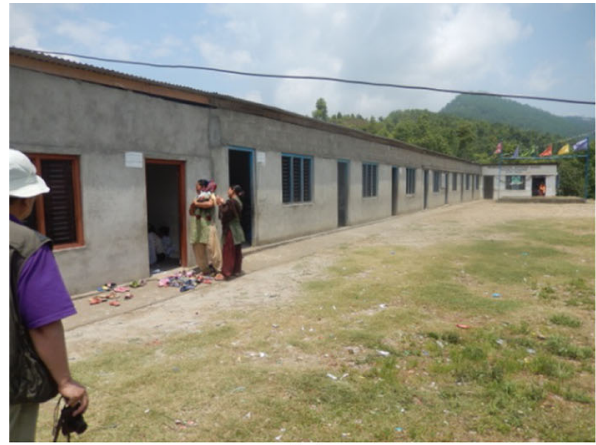

(a)

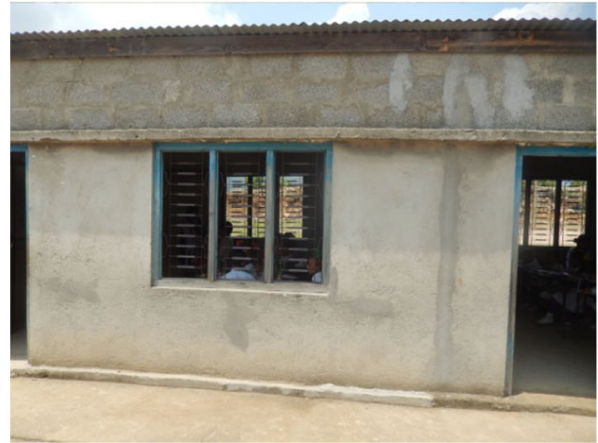

(c)

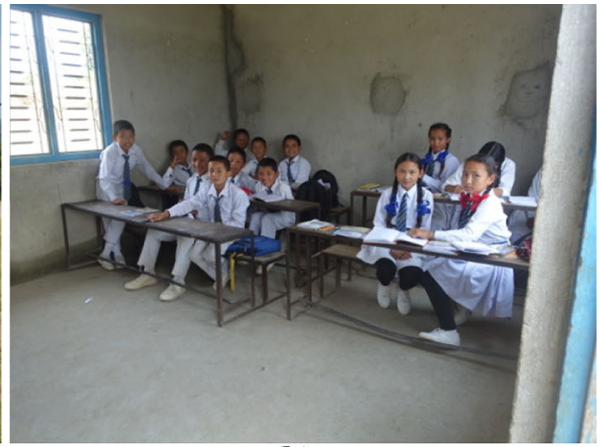

(b)

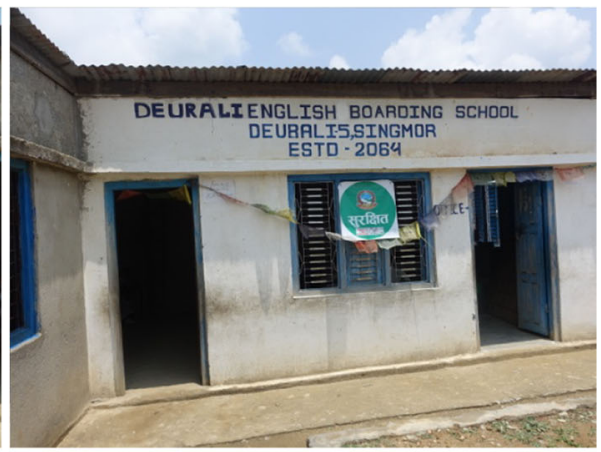

(d)

Fig. 16 Seismic damage to Deurali English Boarding School, constructed of light brick cement-bonded masonry. a Outside view. b Inside view. c Light brick over the heavy brick. d The school was verified to be safe as marked by the green sign

roof was almost intact, with only a minor crack at the corner of the roof. Details of the seismic damage are shown in Fig. 15. There was a green sign at block A, indicating the ichnographic layout of seven school buildings and the status evaluation results from the local government. However, we only found six class buildings, blocks A to F, and building 6 marked on the green sign could not be identified. By comparison, buildings 1-5 clearly corresponded with blocks A-E, and building 7 corresponded with block F. The uncertainty did not cause us any trouble because only one building with a red sign was clearly marked on block D. All others were evaluated as safe by the local government.

We were interested to see that an old RC frame was severely damaged during the main shock, but the crack closed during the aftershock, leading to no further damage (see the bottom left panel of Fig. 15, marked unknown). This was just a happy coincidence.

\subsection{Deurali English Boarding School}

This cement-bonded masonry bungalow was located at Deurali-5, Singmor, ESTD—2064, on a hilltop. It had only minor cracks around the window and door holes (Fig. 16a), which had already been fixed by filling with cement, as shown in Fig. 16b. One typical difference from the other masonry structures we encountered is that a large lightweight masonry block was used for the wall above the window and door lintels (Fig. 16c). A timber frame 


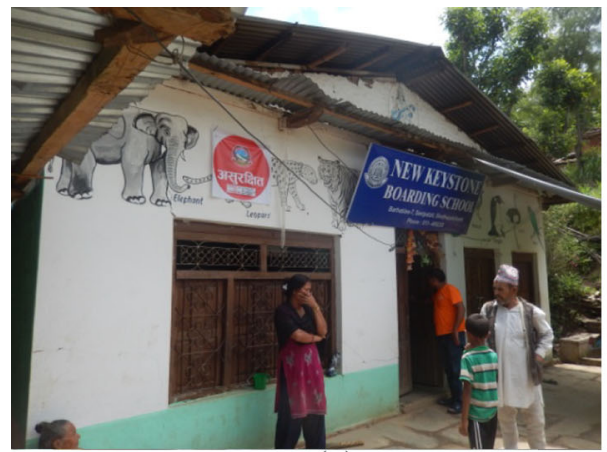

(a)

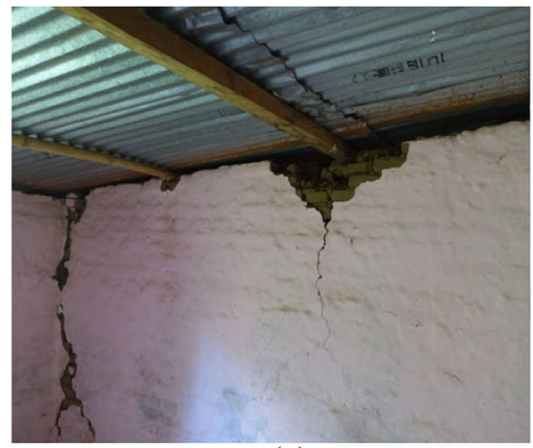

(c)

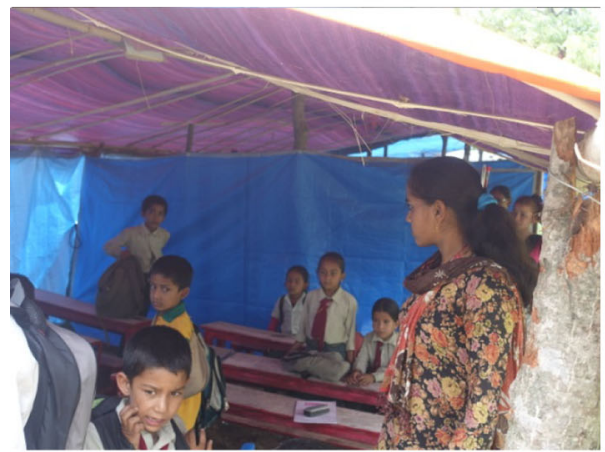

(f)

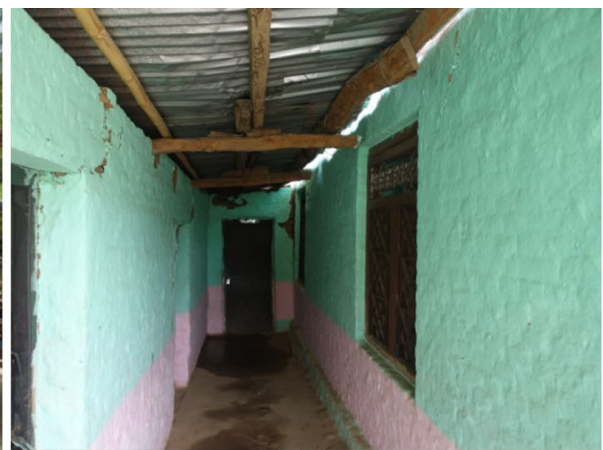

(b)



(d)

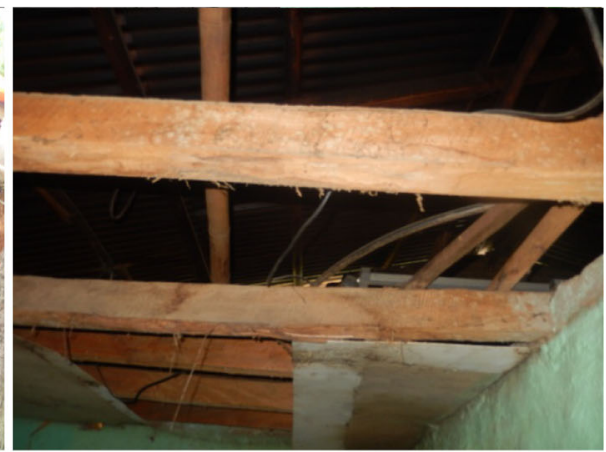

(g)

Fig. 17 Seismic damage to New Keystone Boarding School, constructed of low-strength cement-bonded masonry with simple timber frame roof with light corrugated plate. a School name. b The corridor. $\mathbf{c}$ Cracks of the wall under beam. d Severe cracks at the windows hole. e The corridor viewed from the opposite direction. f Temporary tents for teaching. g Electricity wires arranged around timber frame

covered with a lightweight CGI sheet was used for the roof. Clearly, the construction philosophy was for the local artisans to use a lighter superstructure for safety. The building was graded as safe by the local government (Fig. 16d). 


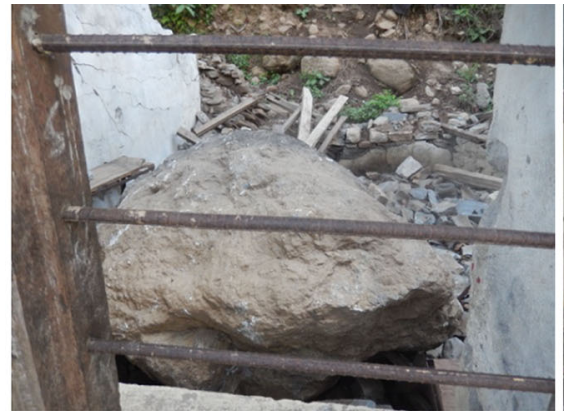

(a)

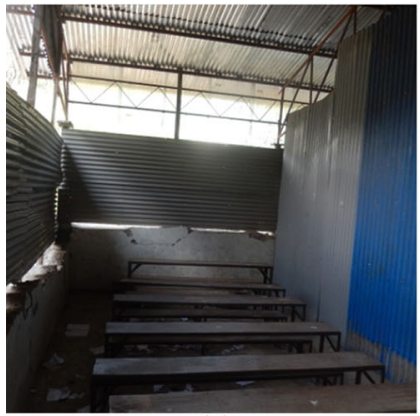

(c)

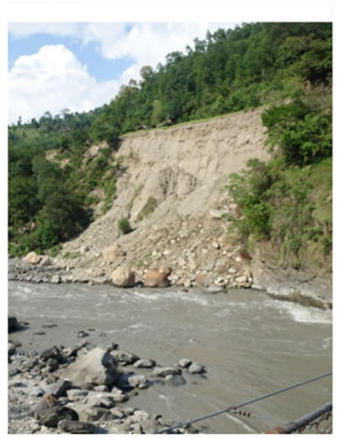

(f)

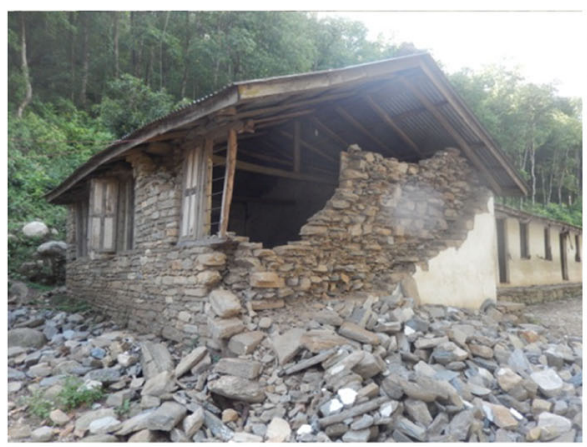

(i)

(g)



(b)

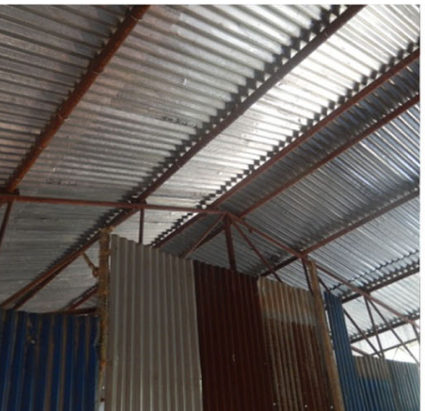

(d)

(e)


(h)

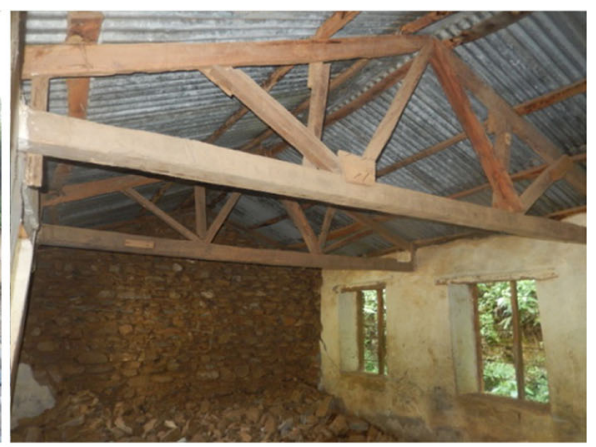

(j) 
Fig. 18 Seismic damage to Thumo Gorka area due to landslide, rock falls and strong ground motion. a Rockfalls knocked into the classroom. b The school located near the hill foot. c The temporary school made of simple frame. d Light CGI sheet as roof. e The other side of the classroom. $\mathbf{f}$ Nearby landslide on a river. $\mathbf{g}$ Nearby landslide on the hill. $\mathbf{h}$ The nearby cement bonded masonry was intact. $\mathbf{i}$ Timber frame with collapsed wall of heavy stone. $\mathbf{j}$ Timber roof frame

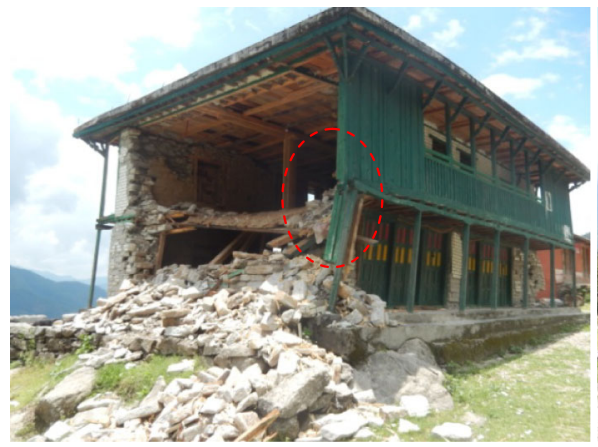

(a)

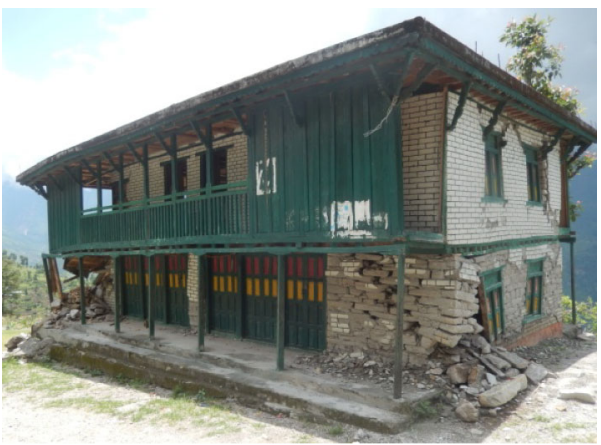

(b)

Fig. 19 Seismic damage to Thumo Gorka area due to landslide, rock falls and strong ground motion. a Out of plane collaspe of masonry wall. b The view of the other corner

\subsection{New Keystone Boarding School}

This aged cement-bonded masonry bungalow was located at Barhabise-7, Sanipalati, Sindhupalchok district (Fig. 17a). Although it was regarded as cement-bonded masonry, the aged cement was weak, as shown in Fig. 17. Severely damaged and partially collapsed masonry walls were observed (Fig. 17b-e). Even with a simple timber frame supporting the light CGI sheet, the joint area of the wall and the timber beam still had a large crack (Fig. 17c). All crew members had been transferred to temporary tents outside the damaged school (Fig. 17f). It is worth noting that the electrical wires were arranged through the timber frame as shown in Fig. 17g, which might have caused a fire hazard.
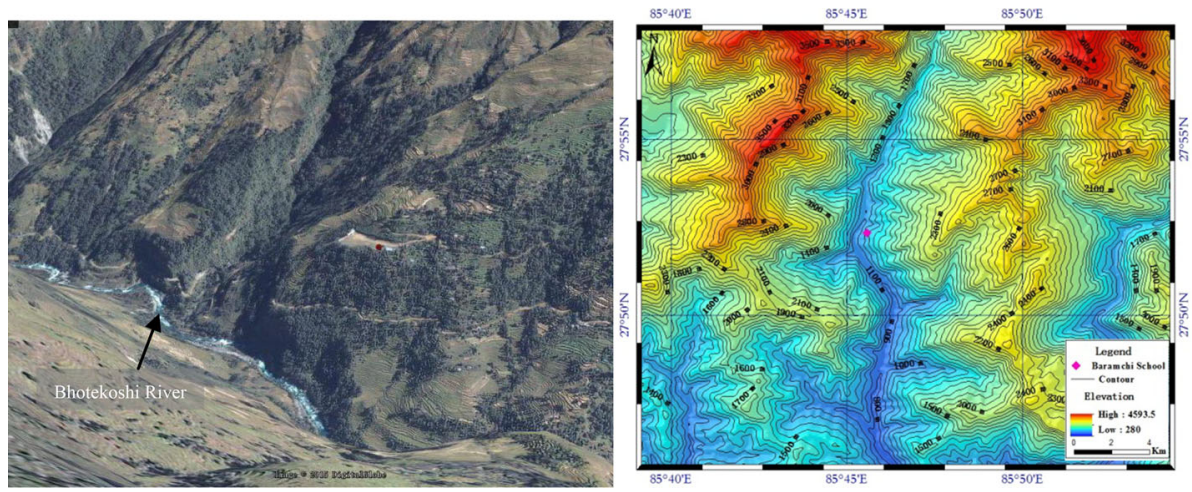

Fig. 20 Topographic map near proposed site for Baramchi School 


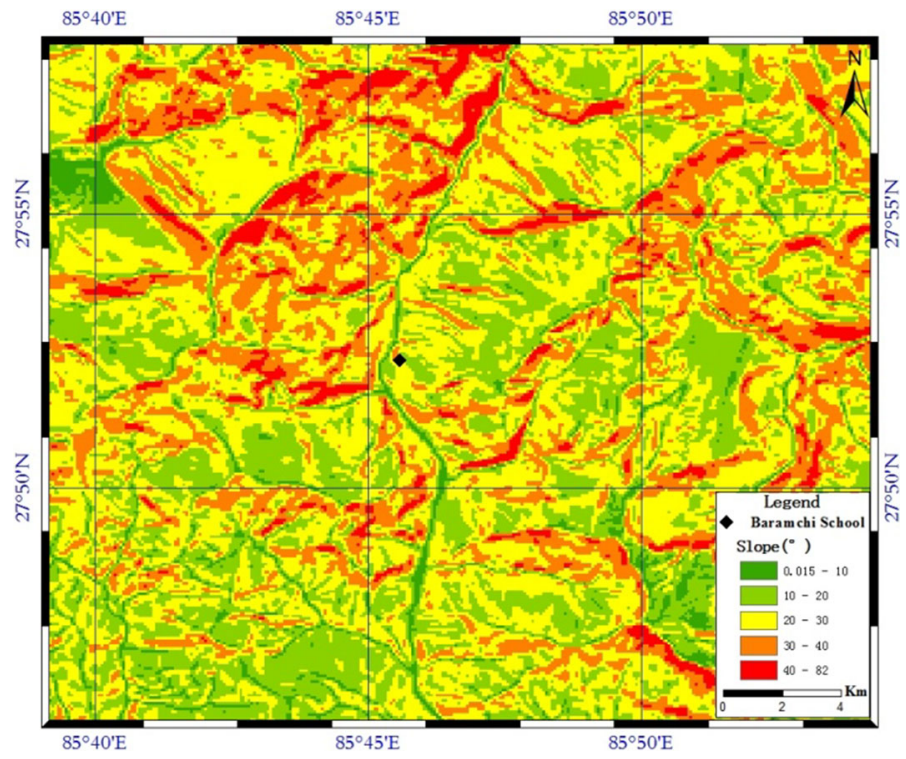

Fig. 21 Gradient distribution around the proposed site

\subsection{Safe distance from slopes}

Landslides are a common geologic hazard in the mountainous area of Nepal. NBC105 stipulates a minimum 15-foot separation from the toe of the slope. However, the field study in Thumo Gorka shows a sad view of a school bungalow damaged by a nearby rockfalls (Fig. 18f, g); the roof was knocked through by rockfalls (Fig. 18a, b). A temporary school (Fig. 18c-e) constructed of a simple steel pipe frame with a light CGI sheet as a cover was set up soon after the main shock. Compared with the partially collapsed mud-bonded stone

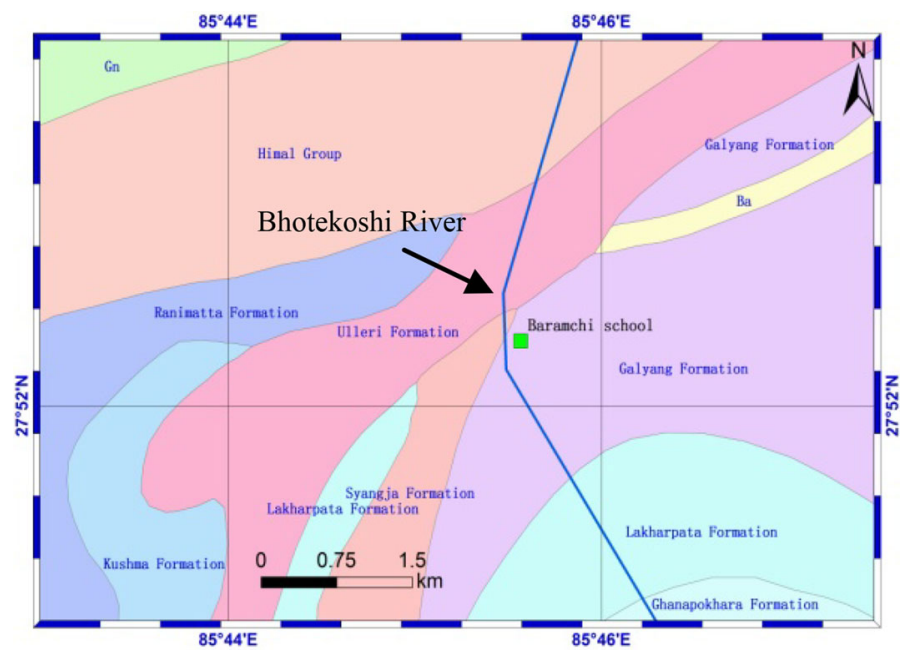

Fig. 22 Geology distribution around the proposed site 




Fig. 23 Phyllite rock was found in the chaotic melange on the west side of the school

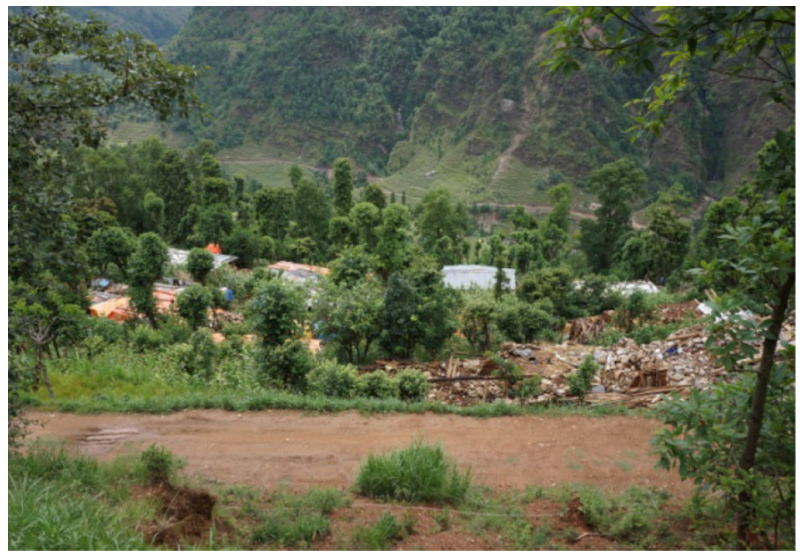

Fig. 24 A completely collapsed stone masonry structure at the school gate (facing west)

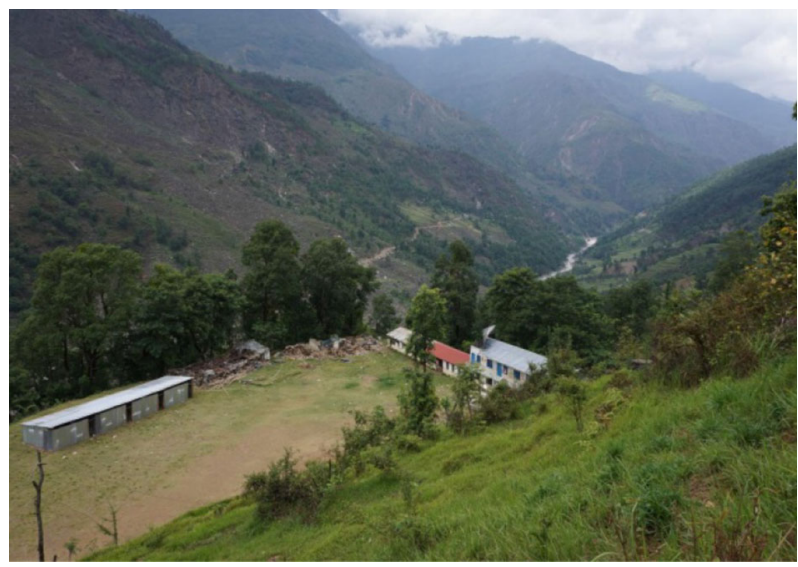

Fig. 25 School houses were severely damaged (facing west) 


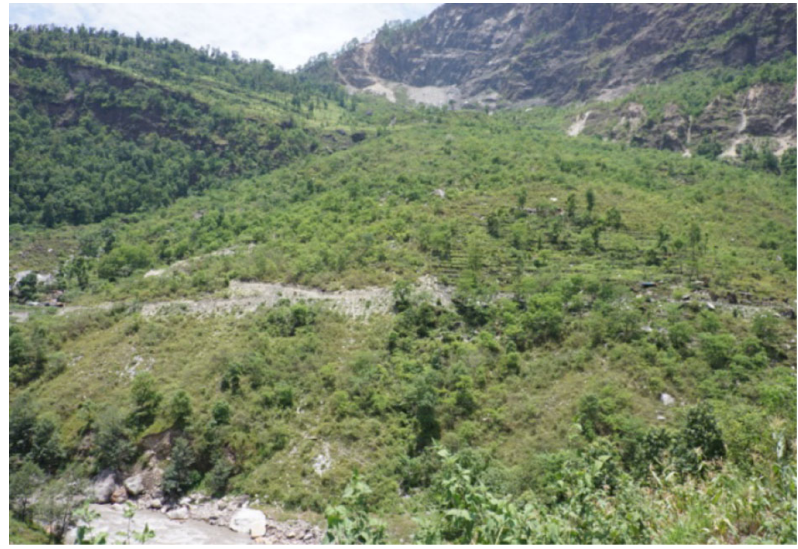

Fig. 26 Large developed ancient landslide body to the west of the main trench (facing west)

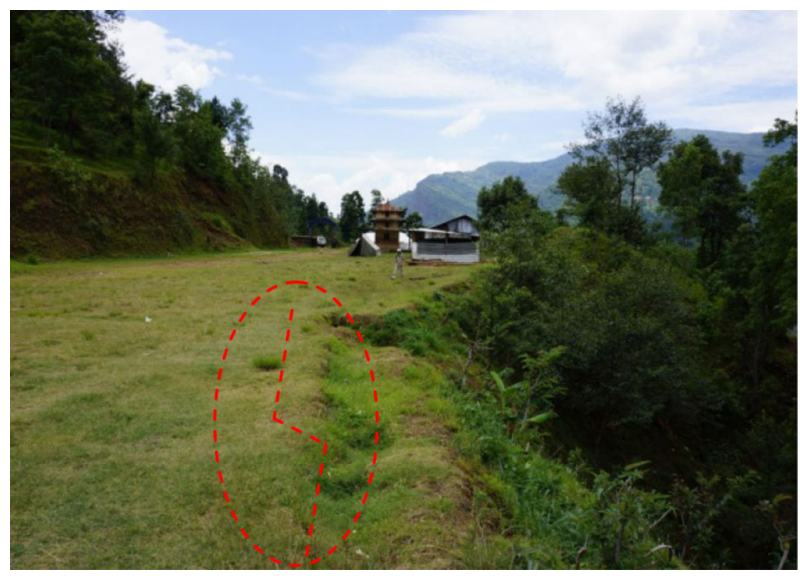

Fig. 27 Land rupture near the south cliff of the school (facing south)

masonry with a timber frame roof (Fig. 18i, j), the newly built RC frame with cementbonded masonry (Fig. 18h) had no apparent damage even though it was only less than 20 m away.

\section{Seismic damage to a timber-framed school}

The small elementary school at Karthali Sindhupalchok was a two-storey timber-framed building with mud-bonded stone masonry. It stood only about $3 \mathrm{~m}$ away from the cliff edge. The wall of one side partially collapsed due to its heavyweight and the low constraint of the out-of-plane direction (Fig. 19a). The timber column at the corner also tended to break at the top of the ground floor (Fig. 19a, marked by red dashed-line circle). The other side partially collapsed at the ground floor (Fig. 19b), and a diagonal crack developed from 
the corners of the windows on the second floor. The thin RC roof was supported by a timber frame. All of the students had been transferred to nearby tents before 14 June.

\section{Safety evaluation of the proposed location for a school in mountainous Baramchi, Sindhupalchok}

The proposed site for Baramchi School by local government is at the transition area from the low Himalayas to the mid-Himalayas. The site is on the east side of a gorge, sitting on the secondary landslide of a large, relatively stable ancient landslide. The altitude of the valley bottom is around $1000 \mathrm{~m}$; the altitudes of the ridges beside it are $2500 \mathrm{~m}$ (Fig. 20). The range of the slope gradients was $20^{\circ}-40^{\circ}$. The Bhotekoshi River flows gently on the west side of the site, at which the slope was around $30^{\circ}-40^{\circ}$ (Fig. 21). The ancient landslides on both sides had been well developed before. No new large landslide was observed during the main shock, except for small-scale rockfalls and/or landslides.

The chaotic melange of the ancient landslide was everywhere within $1 \mathrm{~km}$ of the school. The newly developed alluvial-diluvia deposition was observed around the river on the west side (Fig. 22). Phyllite and killas rock mingled in the deposit to the north side of the school (Fig. 23). No active fault or fracturing of bedrock was observed in our field study.

The proposed site is located at the joint area with a seismic intensity of VIII and near the boundary of the area with a seismic intensity of IX. The stone masonry building around the school completely collapsed. Several aged RC frames also had severe damage (Figs. 24, 25). The ancient landslides on both sides of the north-south valley in Baramchi were large and fully developed (Fig. 26). However, only small-scale landslides or rockfalls were observed in these earthquake sequences. Although the proposed site is located on an ancient stable landslide, the south of the site has a steep gradient and a large relative altitude difference from the bottom. Many cracks have already been observed near the cliff, as shown in Fig. 27. Some of them even connected to form a long visible crack, which is a sign of a potential landslide. On the other side, the proposed site is far from a mountain of bedrock, with a developed landslide platform on the way, so the probability of a local sudden collapse or rockfalls is low. Even if a sand layer existed, sand liquefaction would not be expected for a site with such a high altitude halfway up the mountain.

\section{Summary and recommendation}

Twelve schools were observed by the authors during the field study from 7 to 22 June. As the common gathering place of the young generation, schools are expected to act as a refuge after an earthquake. Although no building supervision system exists in Nepal, the quality of school buildings receives greater attention than normal vernacular dwellings. This paper summarises the seismic damage to the 12 schools of various structure types, including 6 with RC frames, 5 with cement-bonded or mud-bonded masonry, and 1 with a timber frame. The pros and cons of the local construction technologies are also discussed. Some interesting earthquake phenomena, such as the effects of directivity, site configuration, earthquake sequence and safe distance from slopes, are also discussed.

In general, the performance of the $\mathrm{RC}$ frames $>$ constraint masonry $>$ timber frame $>$ un-confined masonry without ring beam or constructional column $>$ adobe $(>$ means 
'is better than'). The seismic damage matrix of various building types has been summarised by Chen et al. (2016).

1. RC frame: The existence of a weak floor (normally the ground floor) was a prevailing problem. The short column effect caused by the improper design of lateral constraints led to severe damage to the column. Normally, the masonry wall is the first aseismic line of defence, which should consist of fuse-like components for fast replacement after an earthquake. The heavyweight of the local stone masonry walls, the low bonding strength and the insufficient constraint led to out-of-plane collapse and early failure of the wall as the energy dissipating components. Seismic joints are vulnerable components because large relative displacement will occur there. Thus, they should be designed carefully and properly for fast repair. Last but not least, the load transfer path should be clear, and an asymmetric layout should be avoided.

2. Masonry: The cement-bonded masonry generally fared much better than the mudbonded masonry. Lightweight CGI sheets are quite popular in mountainous areas to reduce the dead load and release the burden of the structural components beneath. One building made of cement-bonded masonry with lightweight brick above the window and door lintels and a timber frame roof was observed. Minor cracking was observed in this well-designed bungalow. If a ring beam can be used, the overall integrity could be enhanced. Most of the failure was due to the heavy masonry materials (such as stone and rock) and the low strength of the bonding materials.

3. Timber frame: This lightweight and high ductility structure type fared well with a lightweight masonry wall. However, a high ratio of partially collapsed heavy masonry walls was observed in this study and historically (Sun et al. 2014). Thus, a lightweight and similarly ductile wall (such as plank) and carefully designed mortise and tenon joints are recommended.

4. The forward-directivity effect was considered to be the main reason for the great differences in the intensity of damage between two perpendicular directions of RC frames. Although the wave propagation direction could not be predicted in advance, it is a warning that the most vulnerable direction of seismic input should be examined during the design process.

5. The site effect played an important role in the final fate of the RC frames. The uneven swing force during the earthquake due to the unequal resistance stiffness supported by the ground tends to push the building in the weakly supported direction. This was a common phenomenon on a suddenly raised divide at Charikot; the counter method should be used to guarantee the safety of structures in this situation.

6. As demonstrated by many historic examples, the earthquake sequence normally intensifies the seismic damage because the plastic deformation that accumulates during the additional seismic input leads to larger ductility-in other words, damage. However, in a two-storey aged RC frame at Thankot, a large open crack closed again during a long-distance aftershock. Of course, it is not reliable to count on luck. However, if a proper movable structure could be designed with a damping instrument installed, then the 'open' or 'closed' nature of a 'crack' becomes an energy dissipating behaviour, rather than damage.

7. The safe distance from the slope as stipulated by the NBC 105 was not sufficient for such a large earthquake in a landslide-prone mountainous area. Countermeasures should be proposed for the limited available land, which hardly meets the requirements. 
The major reason for the mega lost during these earthquake sequences could be: soil foundation interaction (for building on the riverside and cliff, the unbalance swinging force during the earthquake tend to push the buildings into the river or off the cliff), large input load (the available seismic records and the predicted PGA/PSA have been analysed in the paper, which suggests that the places near epicentre and places with adverse site condition, e.g. in high altitude, are expected have large seismic input) and some design problems (the building materials in some places are quite heavy for the masonry wall, e.g. heavy rocks/stones, which may lead to the out-of-plane collapse due to the low constrain) combined together leaded to the seismic failure. The general situation of buildings is the balance of safety and economy. In China, we also face the similar problem. However, the ring beam structure is recommended in Sichuan province after the great Wenchuan 512 earthquake. The high stiffness and constraint help this type of structure survive. With reasonable financial support, the wisdom of engineers is also needed to design robust enough buildings with limited resources.

Acknowledgements Funding was provided by Scientific Research Fund of Institute of Engineering Mechanics, China Earthquake Administration (Grant No. 2016B-02), China Postdoctoral Science Foundation (Grant No. 2013M531083), National Natural Science Foundation of China (Grant No. 51508535), Natural Science Foundation of Hei Longjiang Province of China (Grant No. LC2012C32).

Open Access This article is distributed under the terms of the Creative Commons Attribution 4.0 International License (http://creativecommons.org/licenses/by/4.0/), which permits unrestricted use, distribution, and reproduction in any medium, provided you give appropriate credit to the original author(s) and the source, provide a link to the Creative Commons license, and indicate if changes were made.

\section{References}

Abrahamson NA (2000) Effects of rupture directivity on probabilistic seismic hazard analysis. In: Proceedings of the 6th international conference on seismic zonation, vol 1, Palm Springs, CA, pp 151-156

Ahmad R, Singh RP (2016) Attenuation relation predicted observed ground motion of Gorkha Nepal earthquake of April 25, 2015. Nat Hazards 80(1):311-328

Boore DM, Stewart JP, Seyhan E, Atkinson GM (2014) NGA-West2 equations for predicting PGA, PGV, and 5\% damped PSA for shallow crustal earthquakes. Earthq Spectra 30(3):1057-1085. doi:10.1193/ 070113EQS184M

Bray JD, Rodriguez-Marek A (2004) Characterization of forward-directivity ground motions in the nearfault region. Soil Dyn Earthq Eng 24(11):815-828

Chaulagain H, Rodrigues H, Jara J, Spacone E, Varum H (2013) Seismic response of current RC buildings in Nepal: a comparative analysis of different design/construction. Eng Struct 49:284-294

Chen H, Xie Q, Li Z, Xue W, Liu K (2016) Seismic damage to structures in the 2015 Nepal earthquake sequences. J Earthq Eng. doi:10.1080/13632469.2016.1185055

Fan W, Shearer PM (2015) Detailed rupture imaging of the 25 April 2015 Nepal earthquake using teleseismic P waves. Geophys Res Lett 42(14):5744-5752

Feng W, Lindsey E, Barbot S, Samsonov S, Dai K, Li P, Li Z, Almeida R, Chen J, Xu X (2016) Source characteristics of the $2015 \mathrm{M}_{\mathrm{W}} 7.8$ Gorkha (Nepal) earthquake and its $\mathrm{M}_{\mathrm{W}} 7.2$ aftershock from space geodesy. Tectonophysics. doi:10.1016/j.tecto.2016.02.029

Galetzka J, Melgar D, Genrich JF, Geng J, Owen S, Lindsey EO, Xu X, Bock Y, Avouac JP, Adhikari LB, Upreti BN, Sitaula BP, Bhattarai TN, Sitaula BP, Moore A, Hudnut KW, Szeliga W, Normandeau J, Fend M, Flouzat M, Bollinger L, Shrestha P, Koirala B, Gautam U, Bhatterai M, Gupta R, Kandel T, Timsina C, Sapkota SN, Rajaure S, Maharjan N (2015) Slip pulse and resonance of the Kathmandu basin during the 2015 Gorkha earthquake, Nepal. Science 349(6252):1091-1095

General Administration of Quality Supervision, Inspection and Quarantine of the PRC (GAQSIQ), Standardization Administration of the People's Republic of China (SAC) (2008) The Chinese Seismic Intensity Scale (GB/T 17742-2008). Release on Nov. 13, 2008 (in Chinese) 
Grandin R, Vallée M, Satriano C, Lacassin R, Klinger Y, Simoes M, Bollinger L (2015) Rupture process of the $\mathrm{Mw}=7.92015$ Gorkha earthquake (Nepal): insights into Himalayan megathrust segmentation. Geophys Res Lett 42(20):8373-8382

National Planning Commission/Government of Nepal (NPCGN) (2015) Nepal earthquake 2015 post-disaster needs assessment, key findings. http://reliefweb.int/sites/reliefweb.int/files/resources/PDNA\% 20Volume\%20A\%20Final.pdf. Accessed 29 Dec 2015

National Population and Housing Census (NPHC) (2011) Government of Nepal, National Planning Commission Secretariat, Central Bureau of Statistics. Accessed 22 Nov 2012

National Seismological Centre (NSC) (2015) Aftershocks of Gorkha earthquake. http://www.seismonepal. gov.np/. Accessed 6 Oct 2015

Nepal National Building Code, Seismic Design of Buildings in Nepal (NBC105) (1994) Government of Nepal Ministry of Physical Planning and Works, Department of Urban Development and Building Construction

Poland C (2009) The resilient city: defining what San Francisco needs from its seismic mitigation polices. San Francisco Planning and Urban Research Association report, San Francisco, CA, USA

Rai DC, Singhal V, Raj SB et al (2015) Performance of residential buildings during the M 7.8 Gorkha (Nepal) earthquake of 25 April 2015. Curr Sci 109(11):2126-2135

Rai DC, Singhal V, Raj SB et al (2016a) Reconnaissance of the effects of the M7. 8 Gorkha (Nepal) earthquake of April 25, 2015. Geomat Nat Hazards Risk 7(1):1-17

Rai DC, Singhal V, Pradhan T, Tripathi A (2016b) Seismic vulnerability of monastery temples of stone masonry in Sikkim Himalaya. Curr Sci 110(10):1947-1957. doi:10.18520/cs\%2Fv110\%2Fi10\% 2F1947-1957

Si H, Midorikawa S (2000) New attenuation relations for peak ground acceleration and velocity considering effects of fault type and site condition. In: Proceedings of twelfth world conference on earthquake engineering, Paper No. 0532

Sun BT, Yan PL (2015) Damage characteristics and seismic capacity of buildings during Nepal Ms8.1 earthquake. Earthq Eng Eng Vib 14(3):571-578. doi:10.1007/s11803-015-0046-x

Sun BT, Zhang HY, Yan PL (2014) Earthquake damage and feature analysis of Chinese traditional timber frame structures subjected to the Lushan 7.0 earthquake. China Civ Eng J 47(3):1-11 (in Chinese)

Takai N, Shigefuji M, Rajaure S, Bijukchhen S, Ichiyanagi M, Dhital MR, Sasatani T (2016) Strong ground motion in the Kathmandu Valley during the 2015 Gorkha, Nepal, Earthquake. Earth Planets Space 68(1):1. doi:10.1186/s40623-016-0383-7

USGS (2015) M7.8-36 km E of Khudi, Nepal. http://earthquake.usgs.gov/earthquakes/eventpage/ us20002926\#scientific_finitefault:us_us20002926. Accessed 20 Nov 2015

Wald DJ, Allen TI (2007) Topographic slope as a proxy for seismic site conditions and amplification. Bull Seismol Soc Am 97(5):1379-1395

Yagi Y, Okuwaki R (2015) Integrated seismic source model of the 2015 Gorkha, Nepal, earthquake. Geophys Res Lett 42(15):6229-6235 